Journal of Social Sciences (COES\&RJ-JSS)

ISSN (E): 2305-9249 ISSN (P): 2305-9494

Publisher: Centre of Excellence for Scientific \& Research Journalism, COES\&RJ LLC

Online Publication Date: $1^{\text {st }}$ October 2017

Online Issue: Volume 6, Number 4, October 2017

https://doi.org/10.25255/jss.2017.6.4.851.868

\title{
Administrative Empowerment and its Role on the Work Teams Performance: A Literature Review
}

\author{
Wea'am Aref Khalayleh*, Dr. Ra'ed Masa'deh**, Prof. Musa Al-Lozi***
}

\begin{abstract}
:
The present study aimed to study in depth the concept and characteristics of administrative empowerment, administrative empowerment and administrative strategy, administrative empowerment and total quality management, methods of empowerment and administrative theories, and the role of administrative empowerment in the performance of the work teams through reviewing books, researches, studies, periodicals and published scientific literature. Further, the researchers reviewed the prevailing theories of administrative empowerment and its relationship to managing the performance of teams.
\end{abstract}

Keywords:

Administrative empowerment, work teams performance

\section{Citation:}

Khalayleh, Wea'am Aref; Masa'deh, Ra'ed; Al-Lozi, Musa (2017); Administrative empowerment and its role on the work teams performance: a literature review; Journal of Social Sciences (COES\&RJ-JSS), Vol.6,No.4,pp:851-868; https://doi.org/10.25255/jss.2017.6.4.851.868.

* MS.c. Candidate at the University of Jordan Business School, Amman, Jordan, ** Associate Professor of Management Information Systems Department, The School of Business, The University of Jordan

*** Vice President for Centers and Community Service Affairs, President of Aqaba Branch, The University of Jordan 


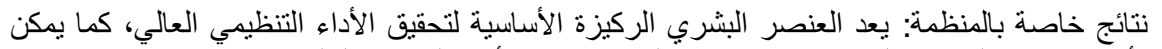

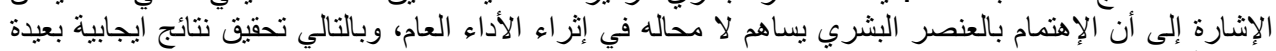

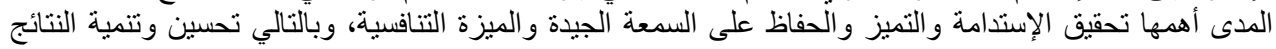

المالية.

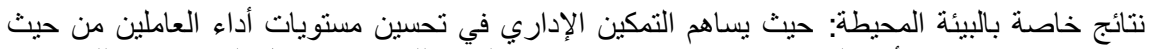

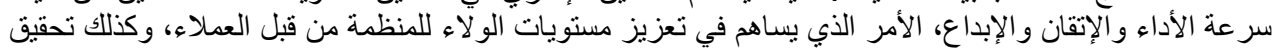

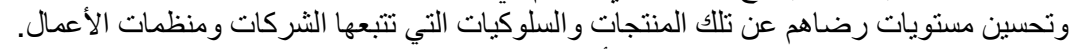

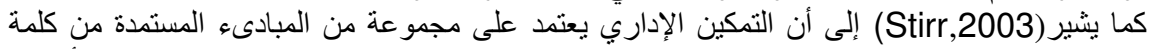

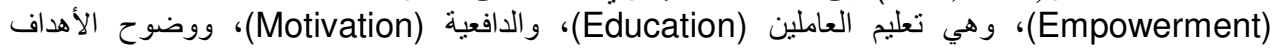

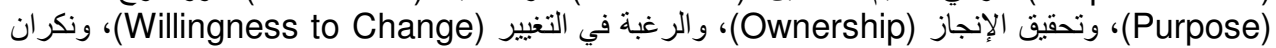
الذات (Ego Elimination) الذي يشير إلى التخلي عن الملذات الثيات الثخصية مقابل تحقيق مصلحه ما، و الإحترام (Respect)

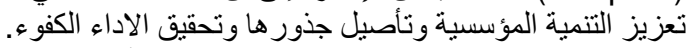

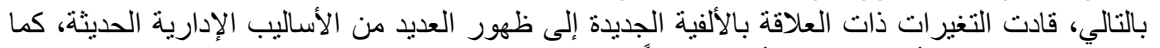

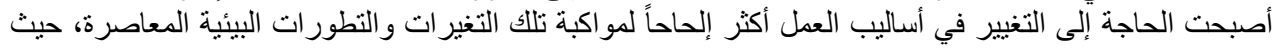

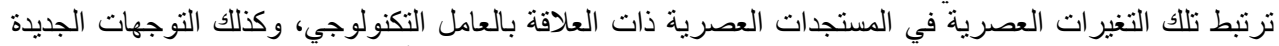

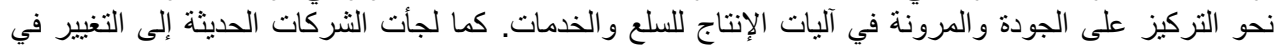

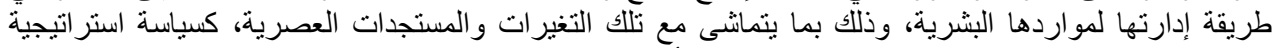

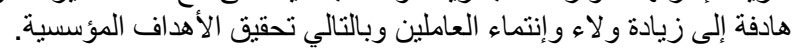
مفهوم التمكين الإداري

قاد التطور في الإدي الفكر الإداري إلى بروز مفهوم التمكين الإداري كأحد المفاهيم الإدارية الحديثة، حيث

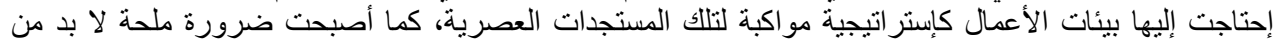

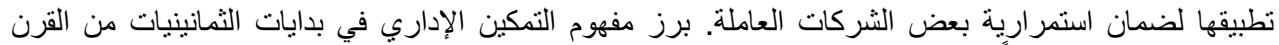

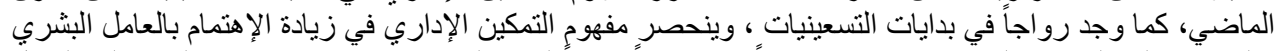

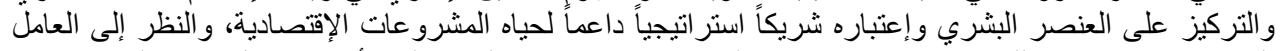

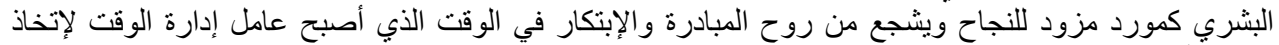

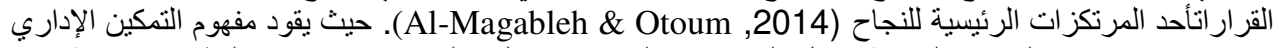

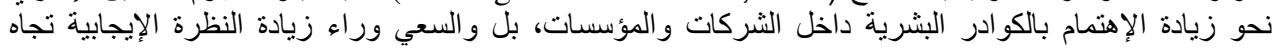

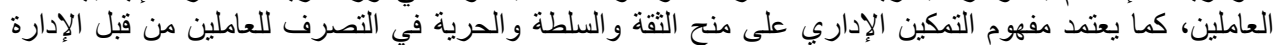

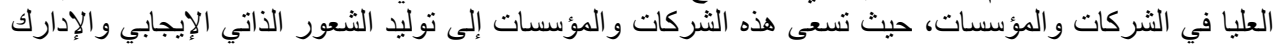

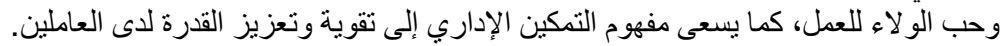

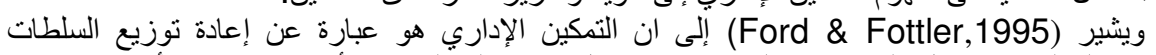

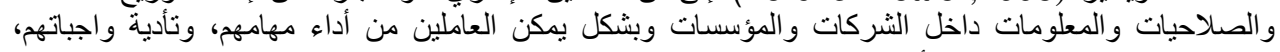

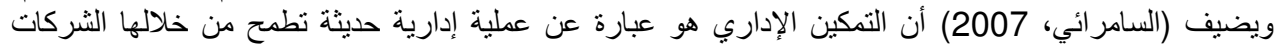

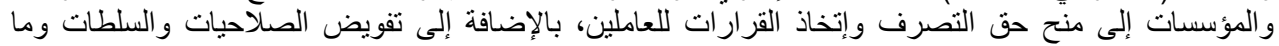

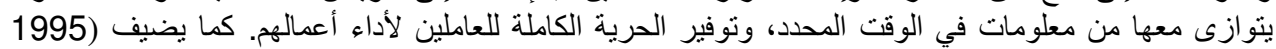
(Bennis \& Townsend,

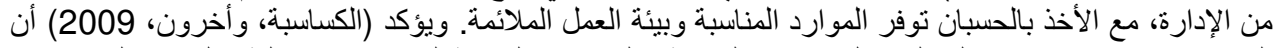

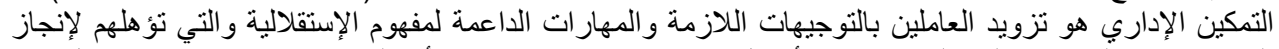

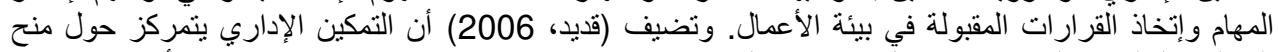

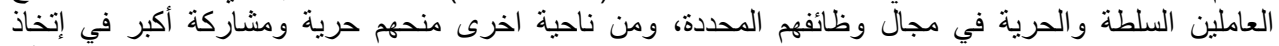

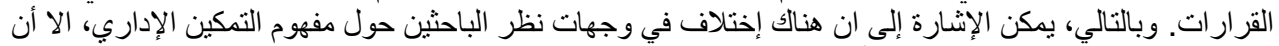

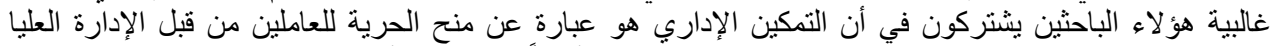

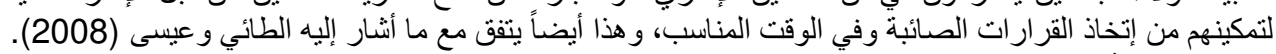

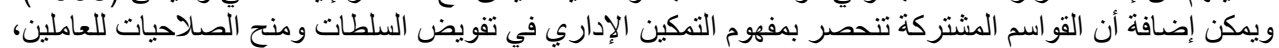

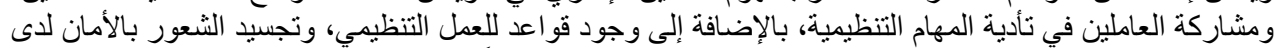

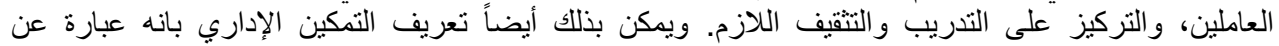

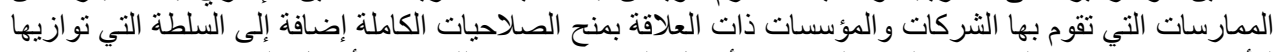

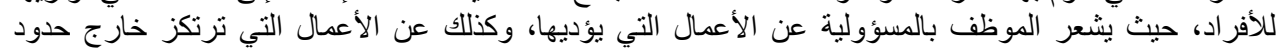


وظيفته. ويضيف (Kruja \& Oelfke,2009) أن التميكن الإداري والوظيفي يرنكز حول تبادل المعلومات و الخبر ات اللازمة التي تمكن الموظفين المساهمة في تأدية مهامهم التنظيمية، علاوة الإدارئ على تحقيق أهدافهر.

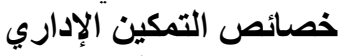

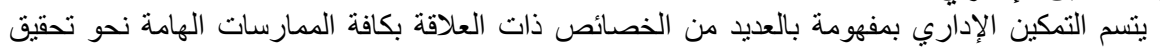

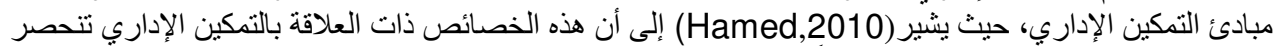

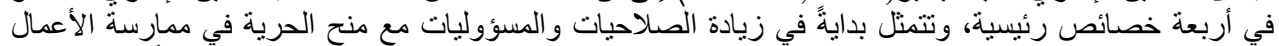

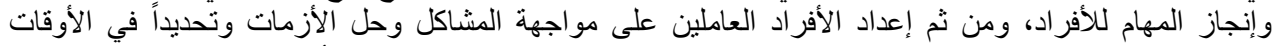

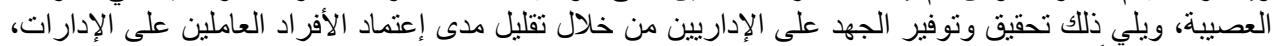

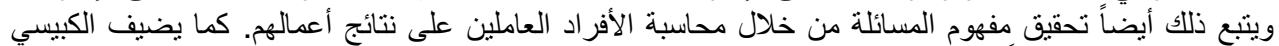

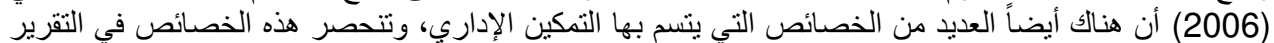

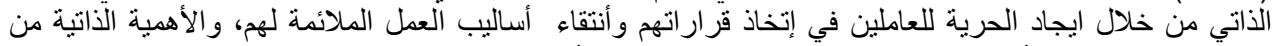

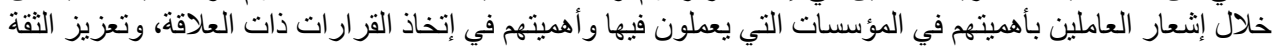

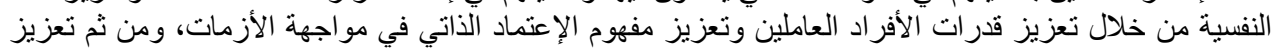

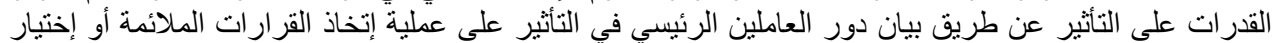

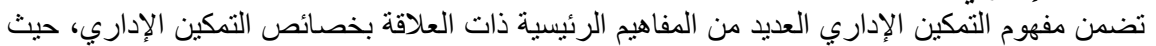

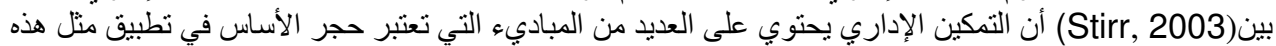

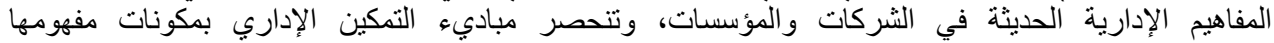

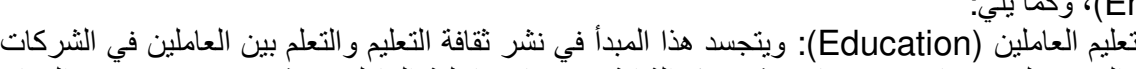
(Empower)

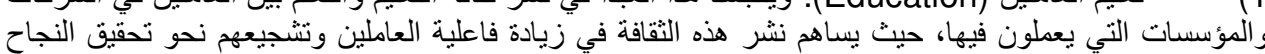

الدافعية (Motivation): حيث ينحصر هذا المبدأ في تشجيع العاملين لتقبل مفهوم التمكين الإداري وبيان

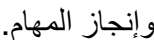

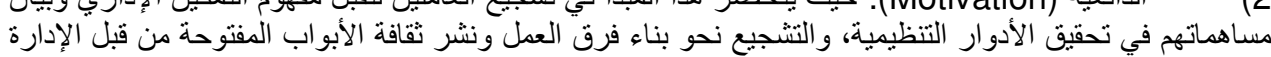
العليا في ملاحظات وتعليقات العادملين.

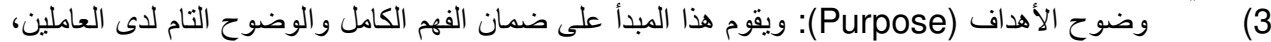

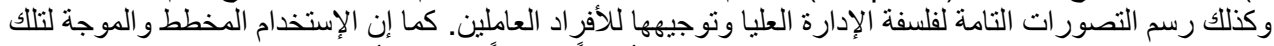

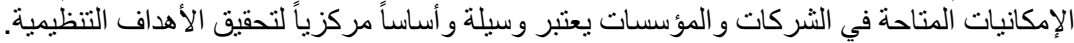

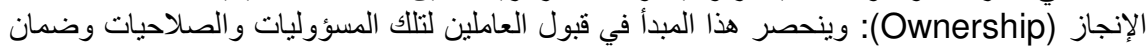

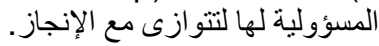

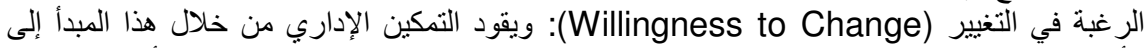

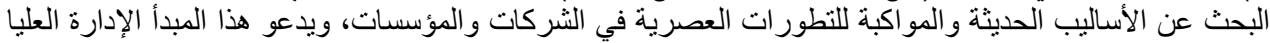

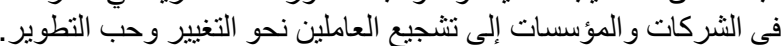

6)

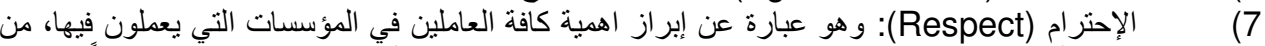

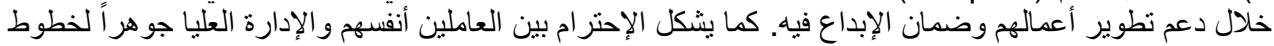

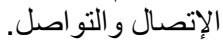

التمكين الإداري والإسلئ الإستر اتيجية الإدارية

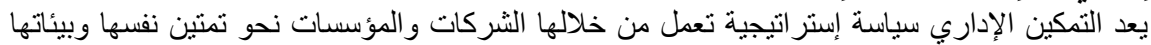

من خلال تبني سياسات تعمل على تدعيم قدر الات وإمكانيات العاملين .كما يتحسن مفهوم التمكين الإداري من خلاتل

$$
\text { التركيز على تلك الممارسات المر غوبة من العاملين في الثركات التئ و المؤسسات. }
$$

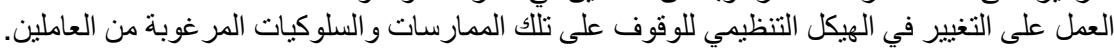

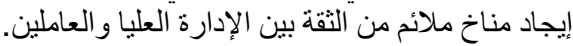

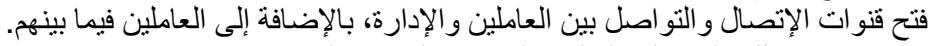

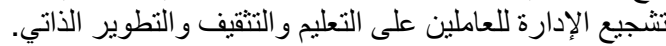

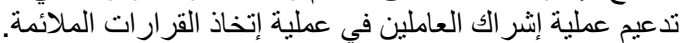

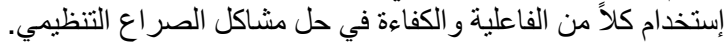




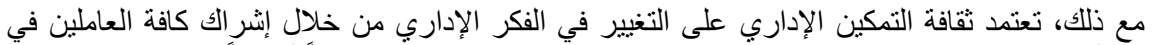

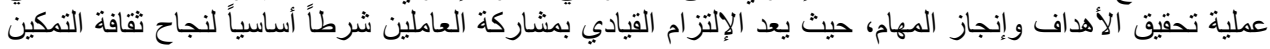

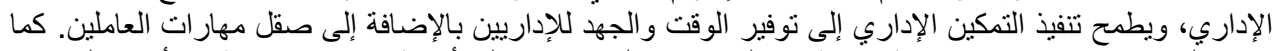

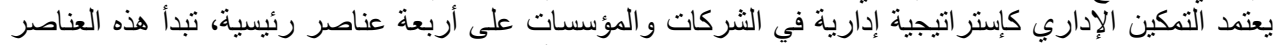

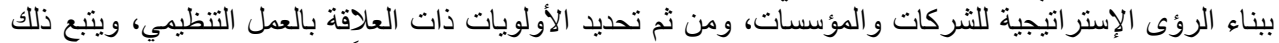

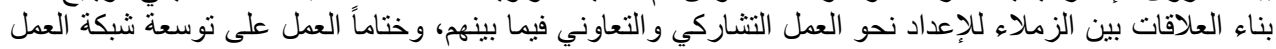

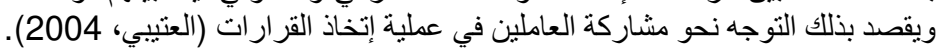

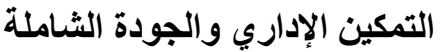

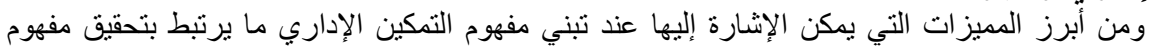

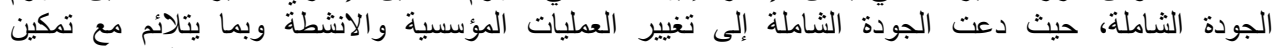

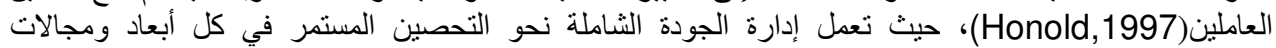

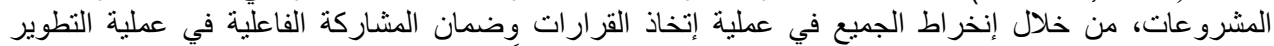

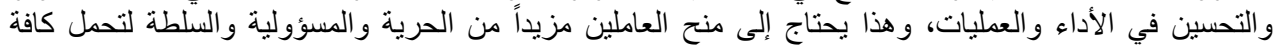

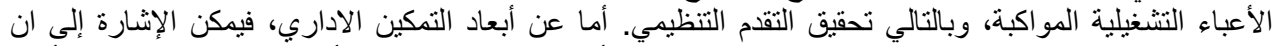

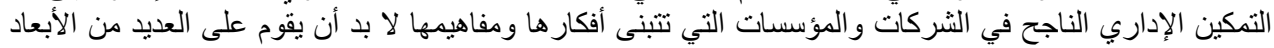

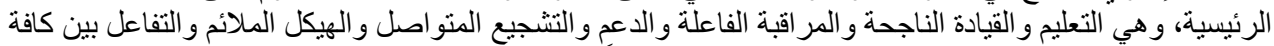

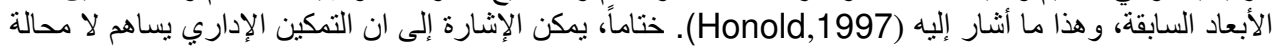

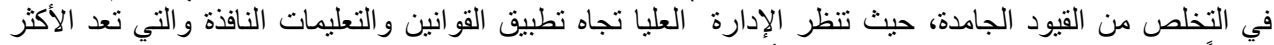

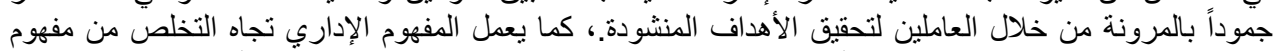

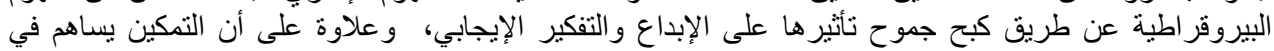

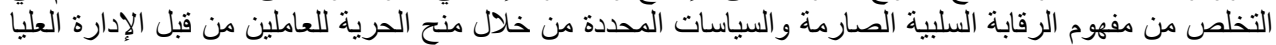

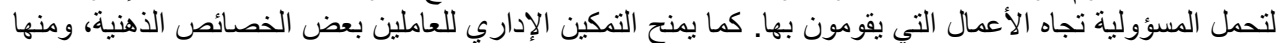
الثعور بالسيطرة و التحكم في تحقيق وتنفيذ الأداء. ما يلي (Aburuman,2016):

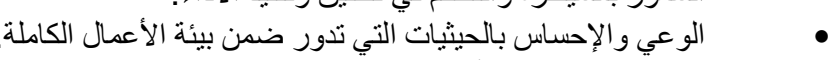

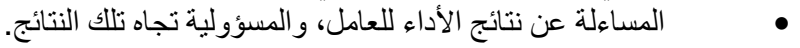

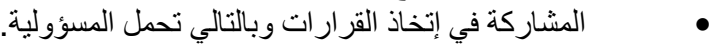

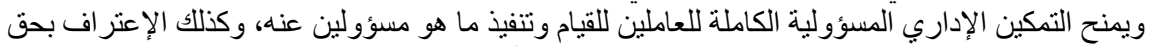

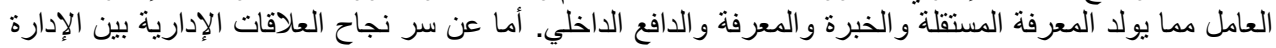

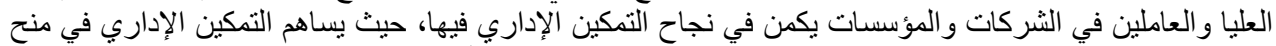

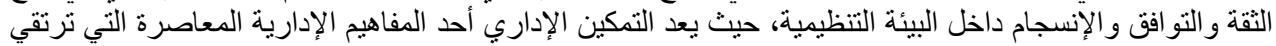

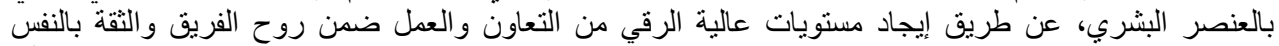

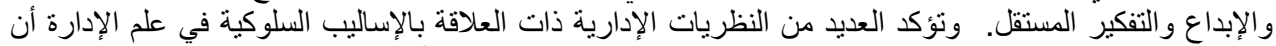

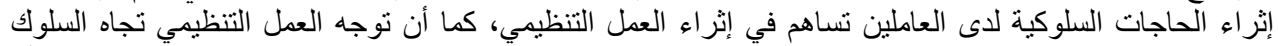

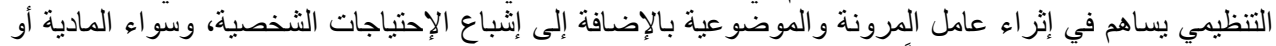

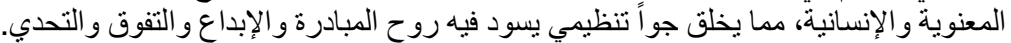

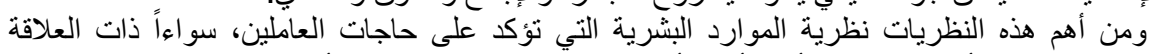

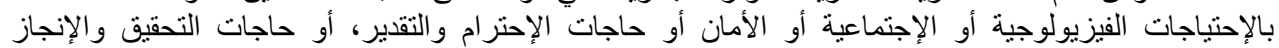

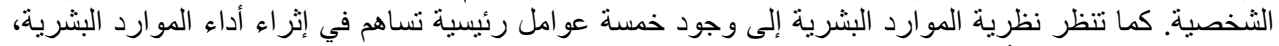

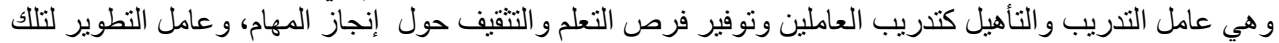

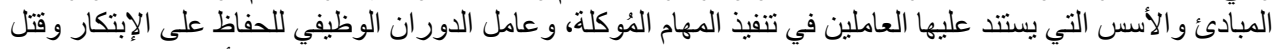

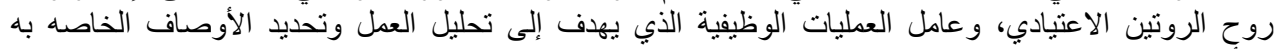

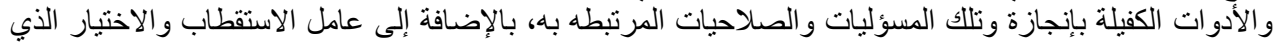

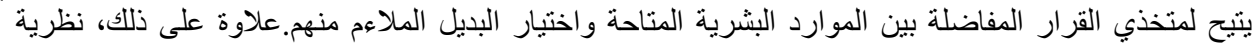

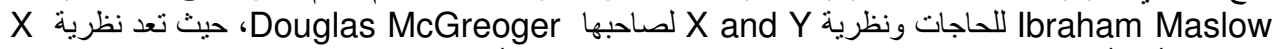
and Y

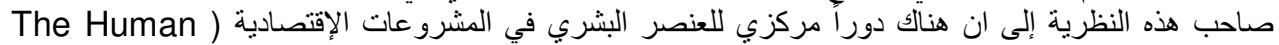
Side of Enterprise

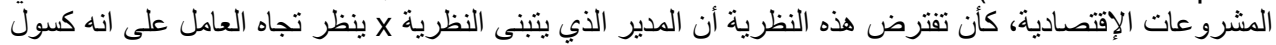

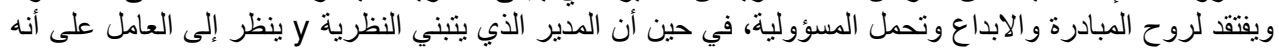




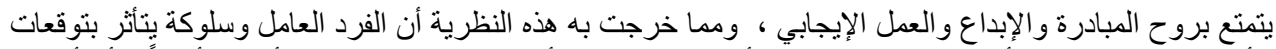

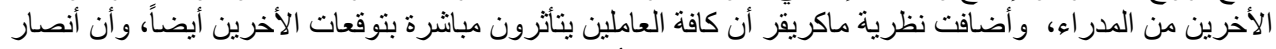

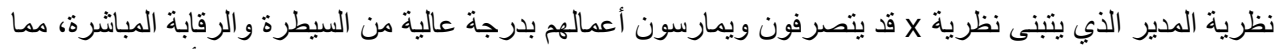

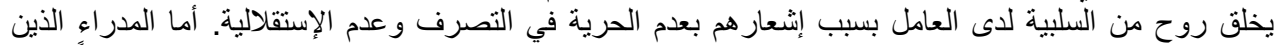

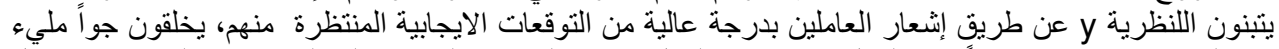

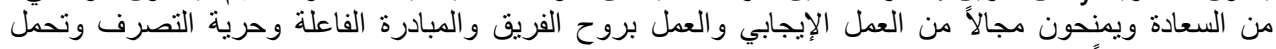

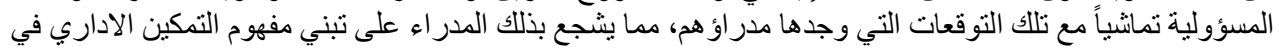

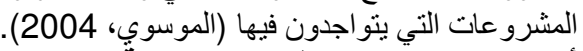

أساليب التمكين والنظريات الإداريةً

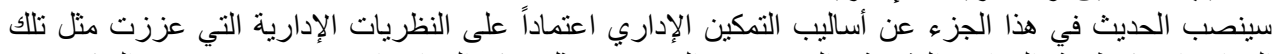

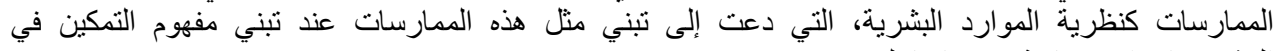

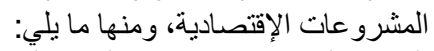

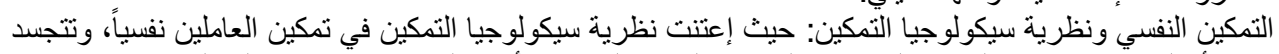

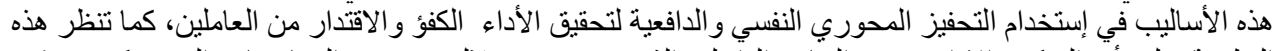

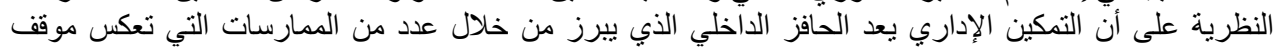

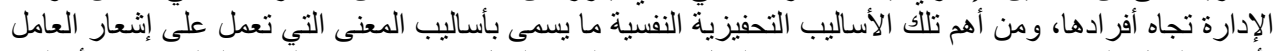

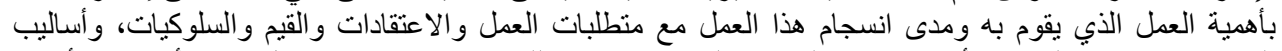

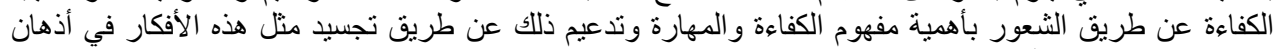

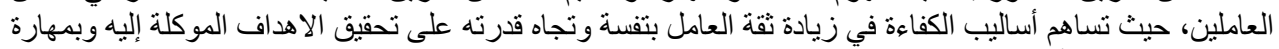

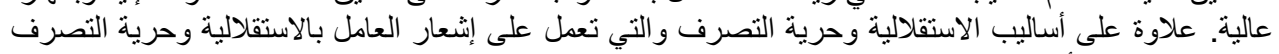

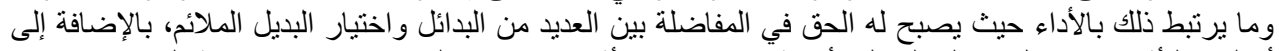

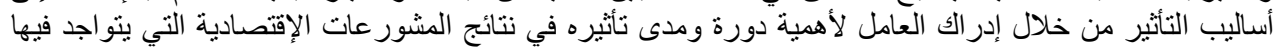

(Honold ,1997)

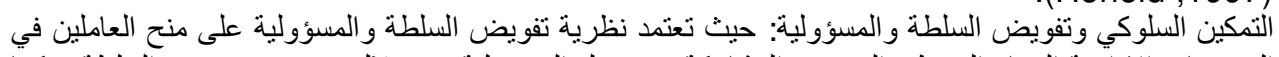

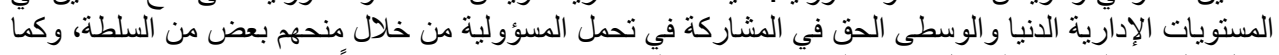

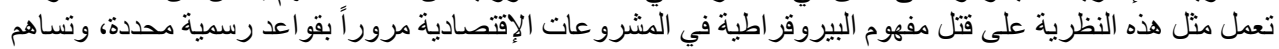

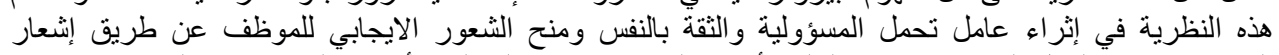

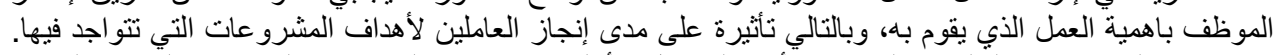

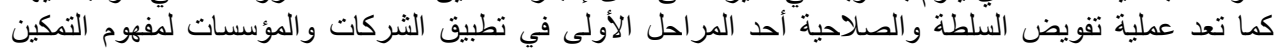

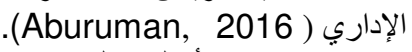

ومن الأساليب المعاصرة الإدارية والنظريات الإدارية الحديثة التي دعت إلى مفهوم التمكين ما يرتبط

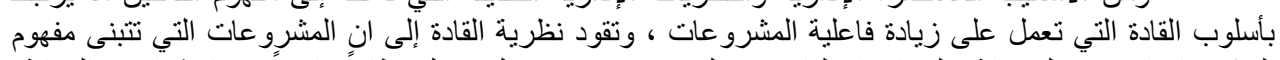

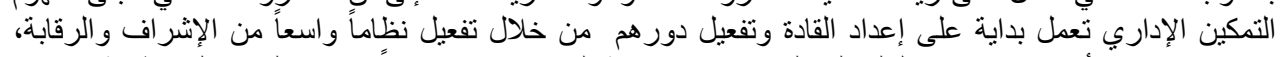

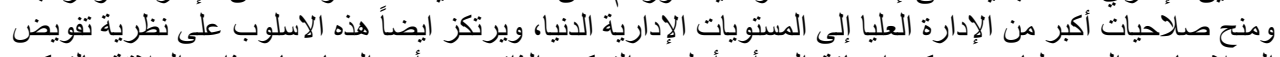

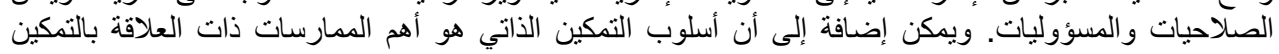

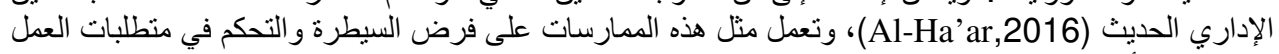

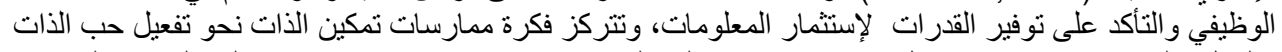

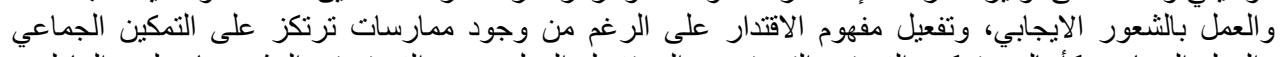

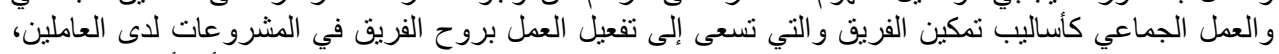

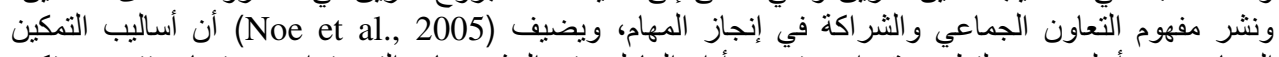

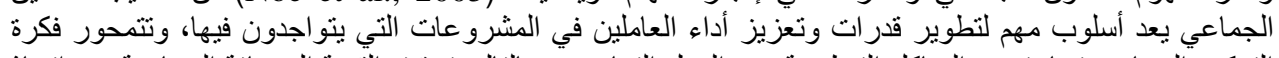

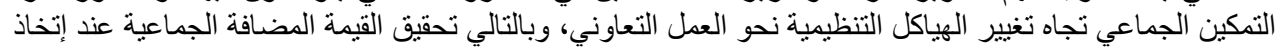

تعد فرق العمل بمثابة ترجمة حديثة للتغير ات و المستجدات الحديثة، حيث تلجأ الشركات ومنظمات الأعمال

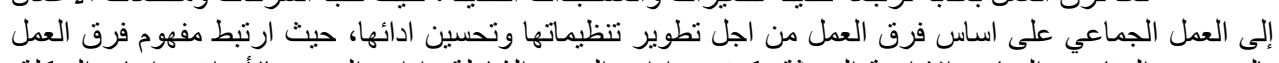

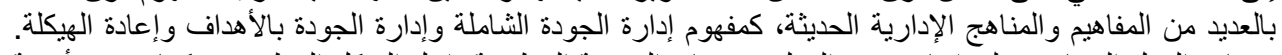

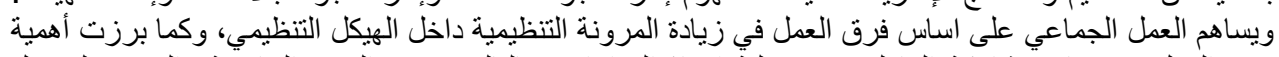

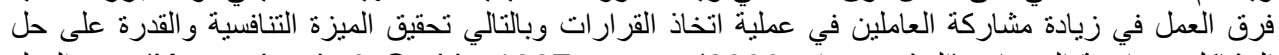

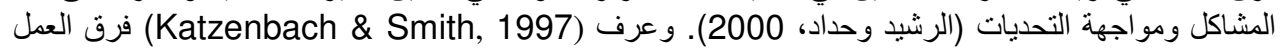




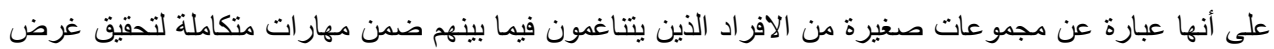

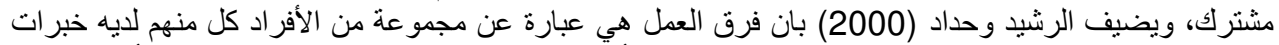

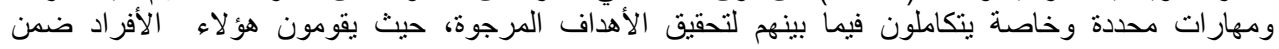

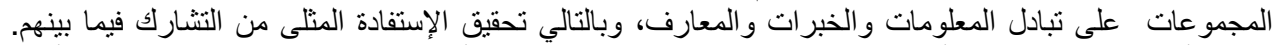

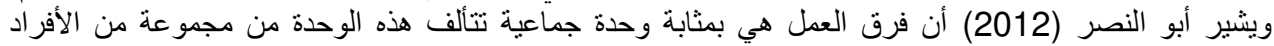

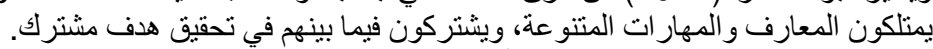

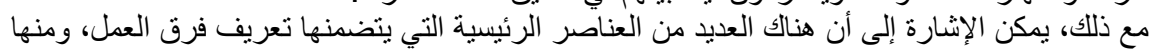

مجمو عة من الأفراد محدودي العدد، على شكل مجمو عات عمل صغيرة. ما يلي (الفايدي، 2008):

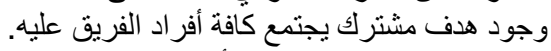

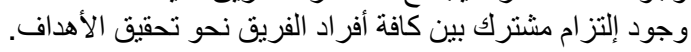

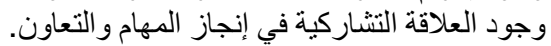

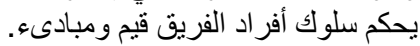

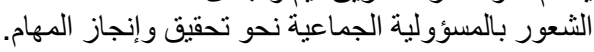

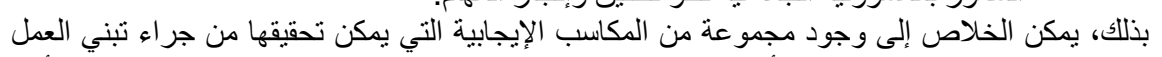

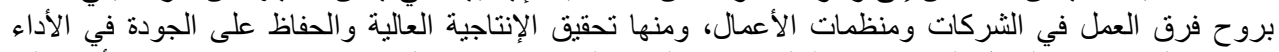

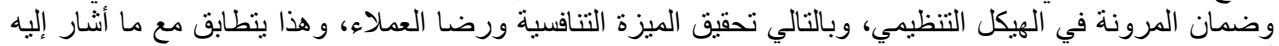
أبو النصر (2012). الأدراسات السابقة

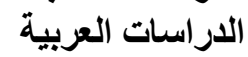

تعددت الدراسات العلمية التي بحثت بمضامين التمكين الإداري ودوره وأهميته في مختلف الجئه الجوانب

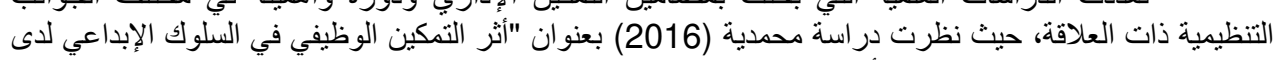

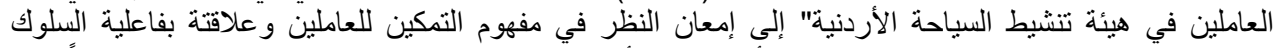

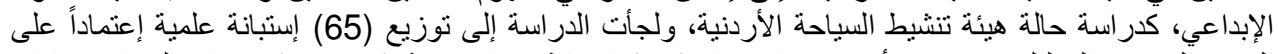

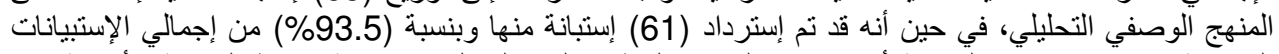

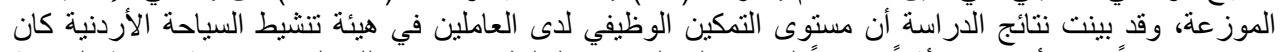

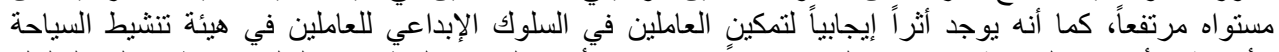

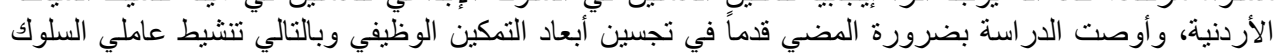

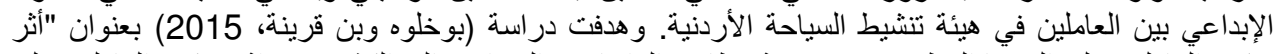

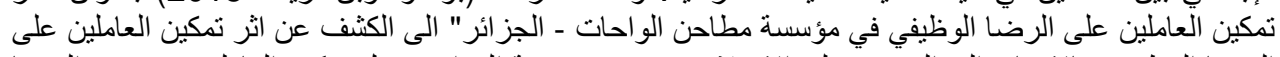

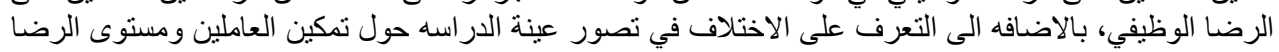

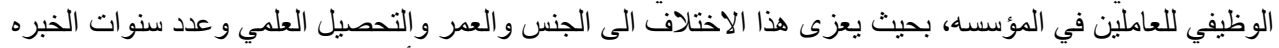

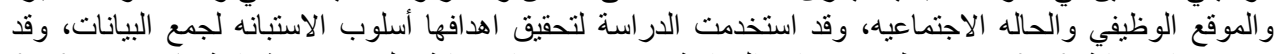

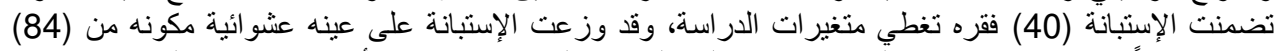

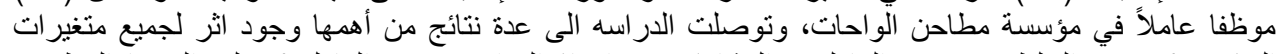

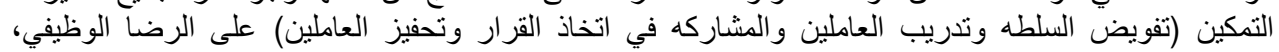

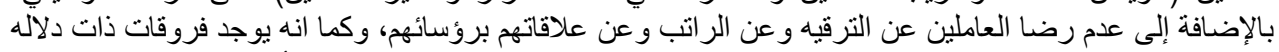

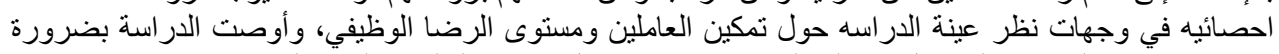

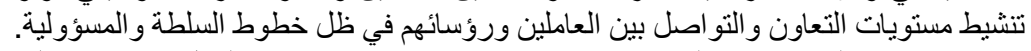

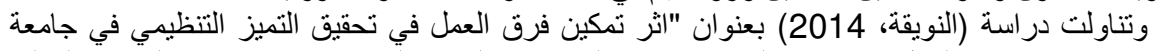

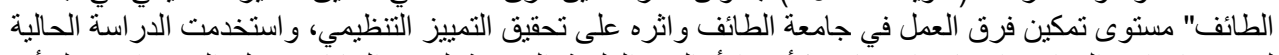

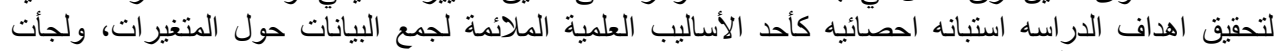

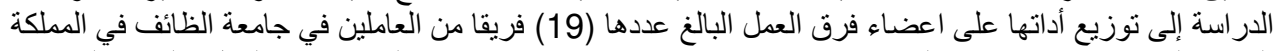

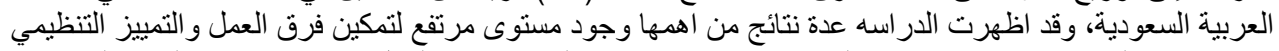

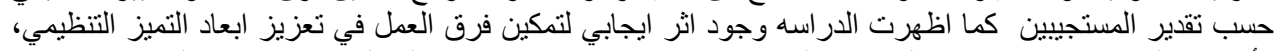

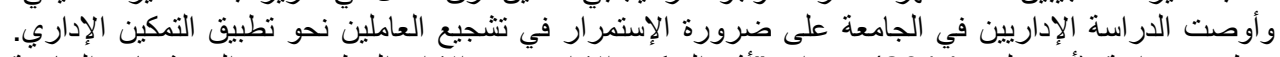

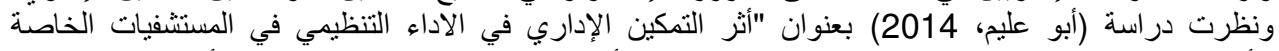

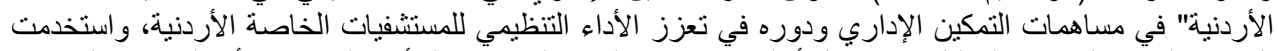

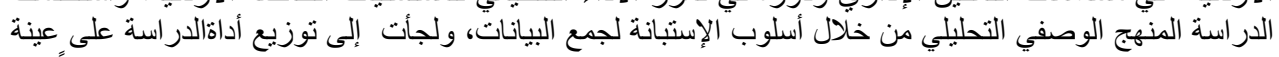

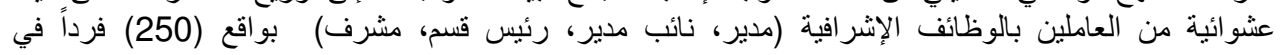




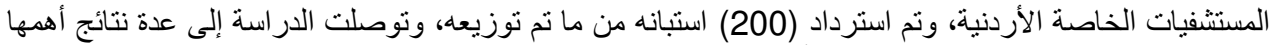

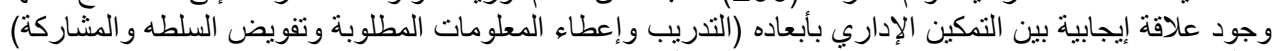

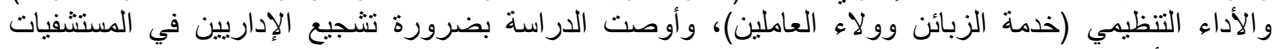
الخاصة الأردنبة على تطبيق التمكين الإداري.

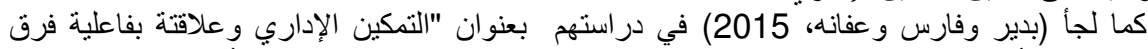

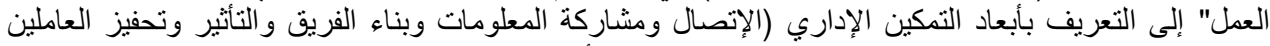

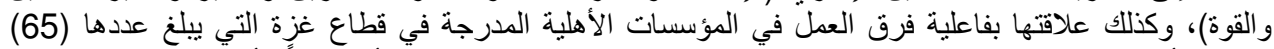

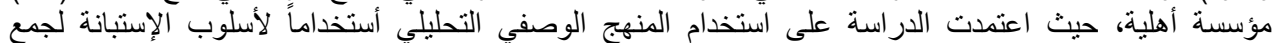

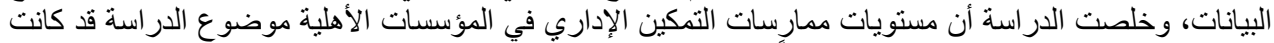

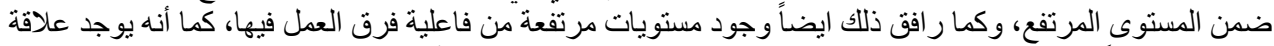

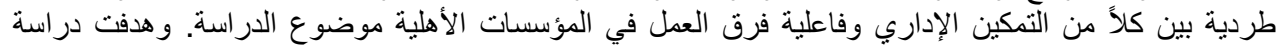

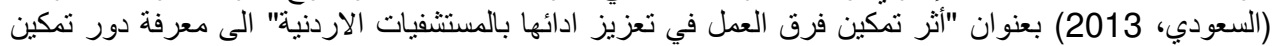

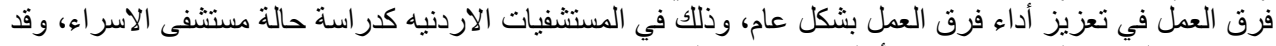

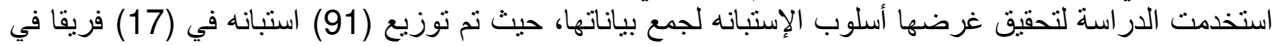

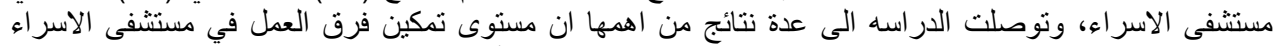

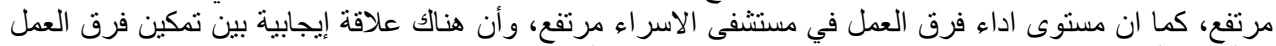

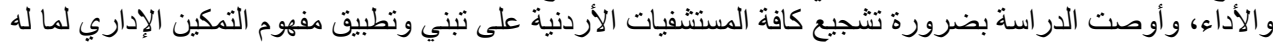
الدور البارز في تحسين أداء المجمو عات التشغيلية داخل الهياكل التنظيمية.

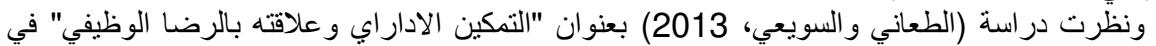

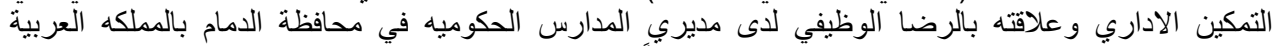

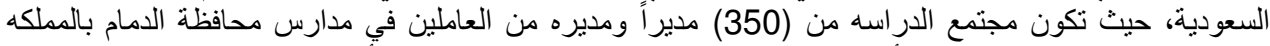

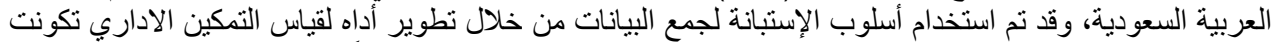

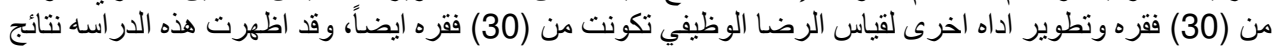

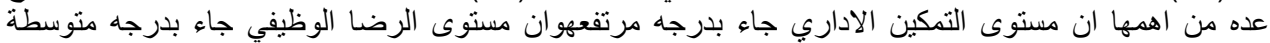

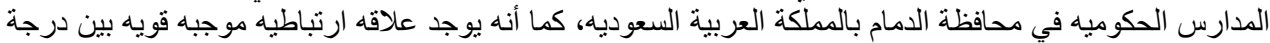

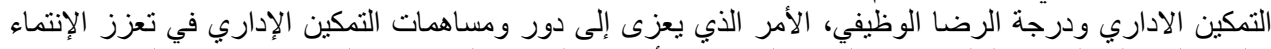

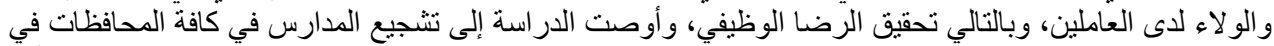

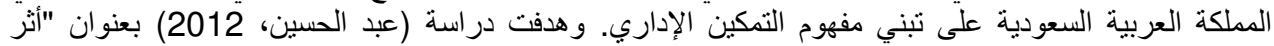

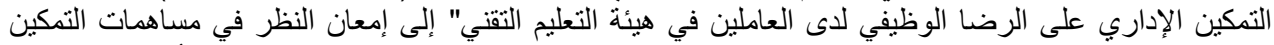

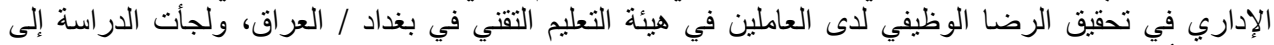

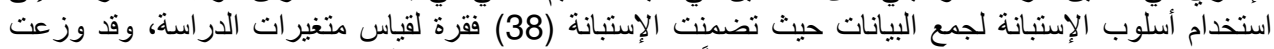

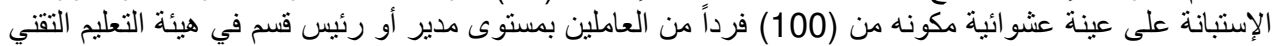

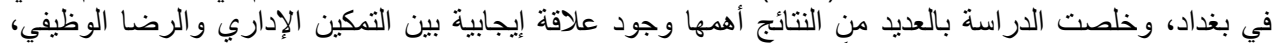

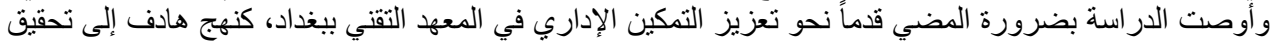
الرضا الوظيفي.

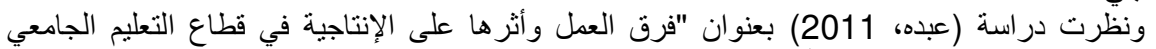

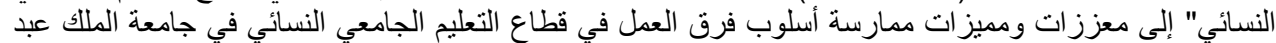

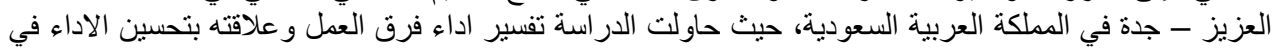

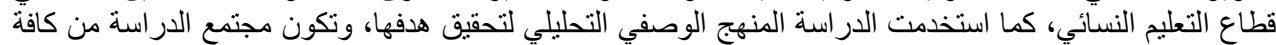

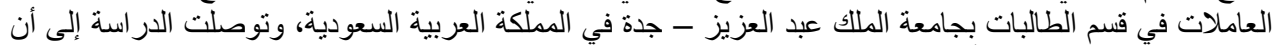

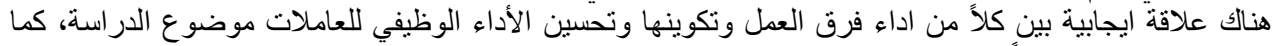

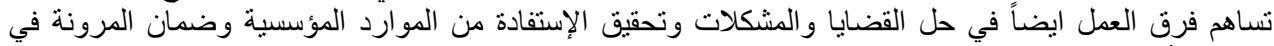

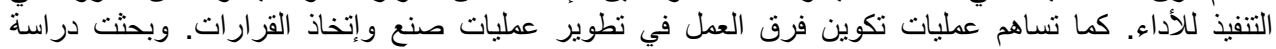

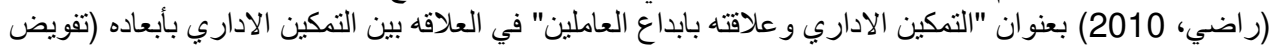

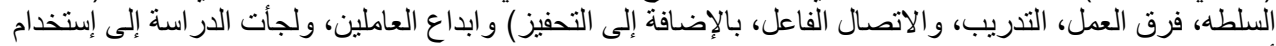

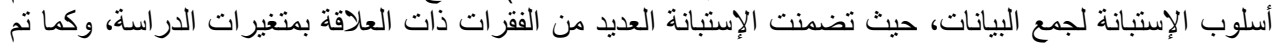

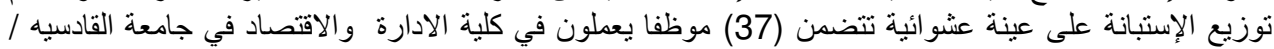

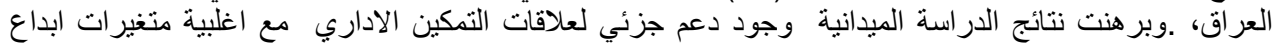

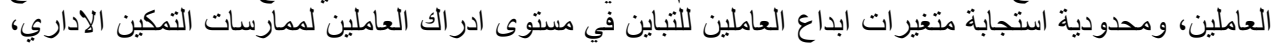


وأوصت الدراسة بالمضي قدماً حول دراسة والبحث في أدوار التمكين الإداري و علاقته بالمتغيرات ذات العات العلاقة

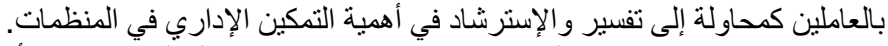

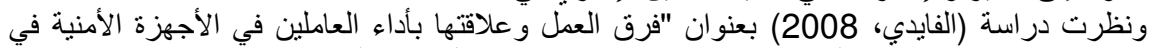

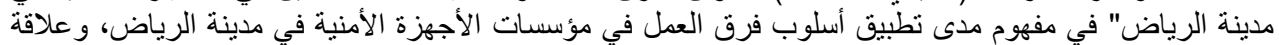

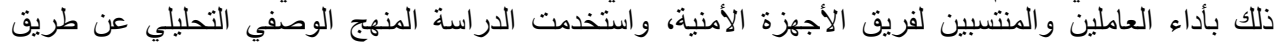

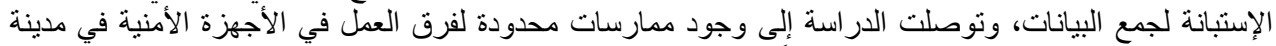

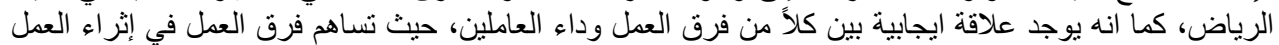

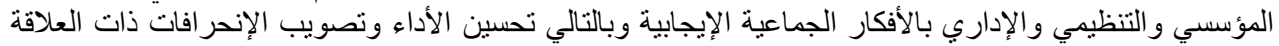

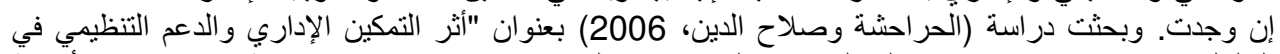

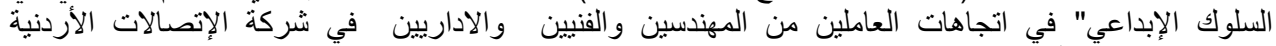
(Orange)

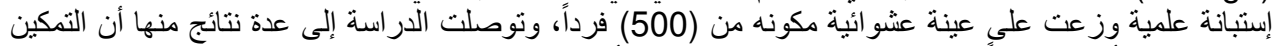

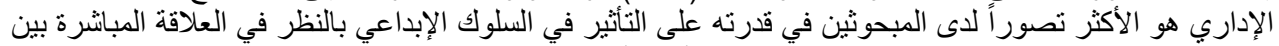

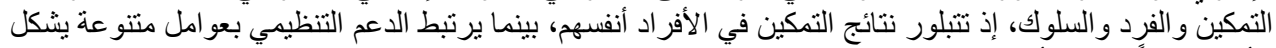

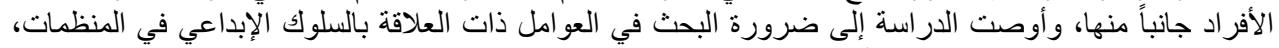

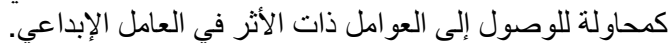

الار اسات الأجنبية

نظرت دراسة (Zhang and Han,2012) بعنوان "تمكين الفريق و السياق التنظيمي: اللامركزية

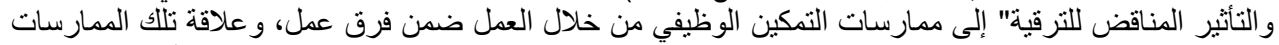

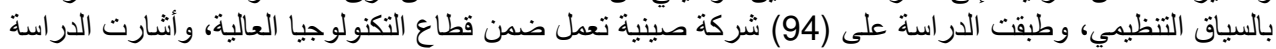

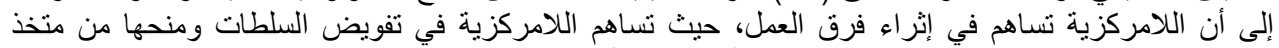

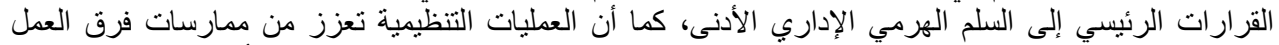

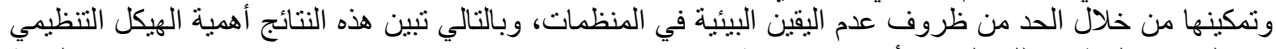

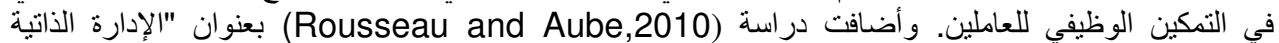

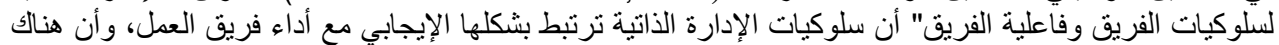

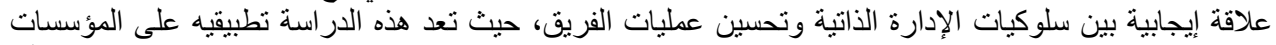

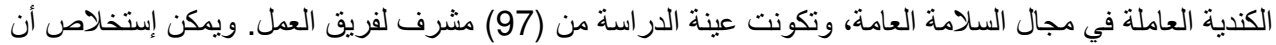

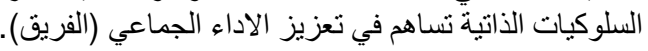

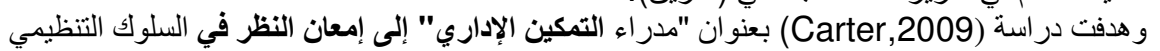

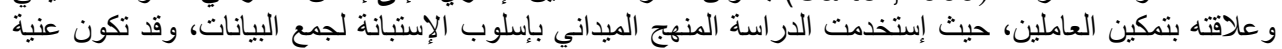

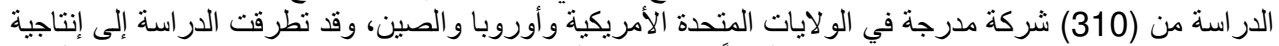

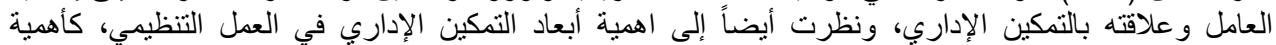

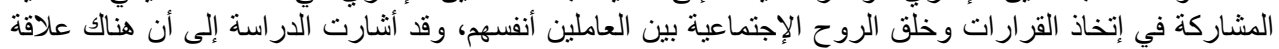

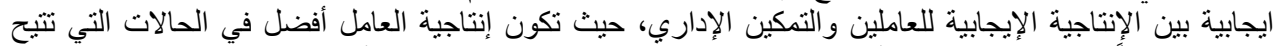

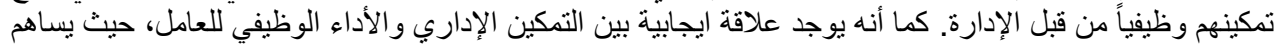

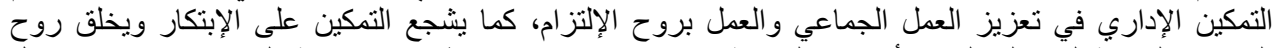

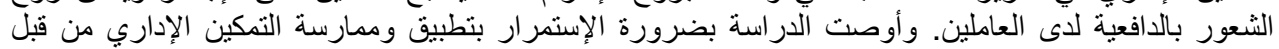

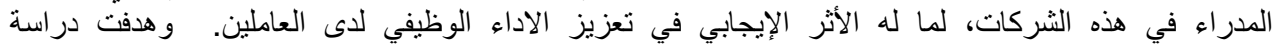

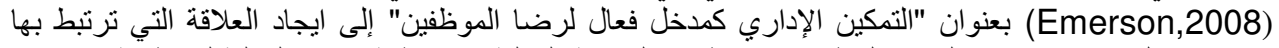

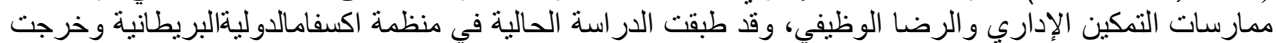

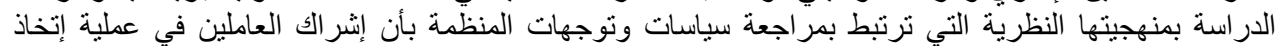

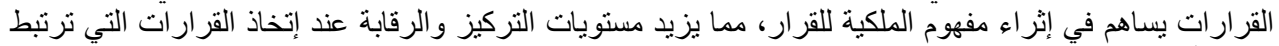

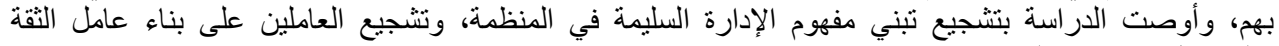
و التو اصل فيما بينهم البعض والبة والإدارة. ونظرت دراسة (Mazhar and Khan,2008) بعنوان "الإدارة التمكين الإداري وأثره على فاعلية عمل الإنس

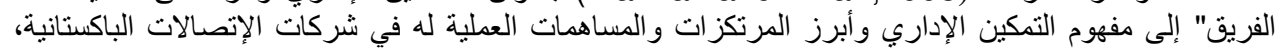

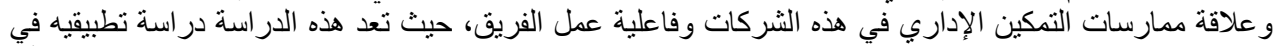

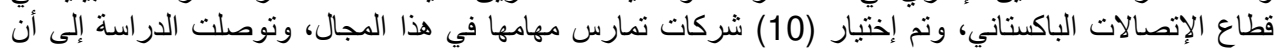

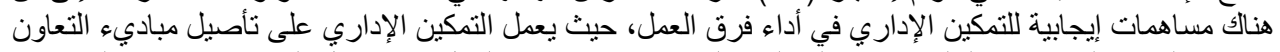

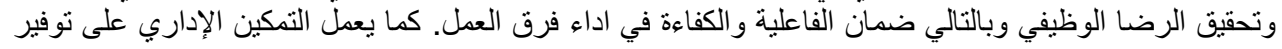




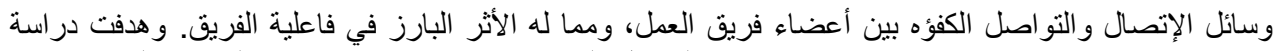
(Mendibil and Mabryde,2006)

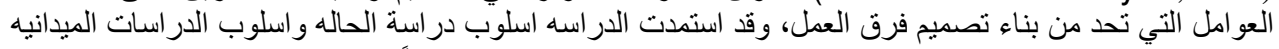

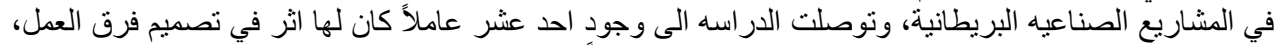

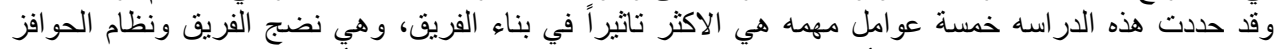

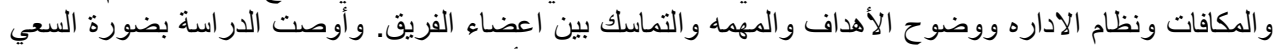

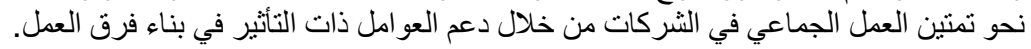

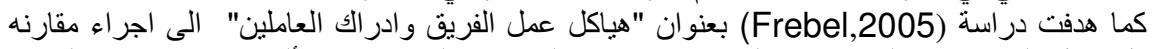

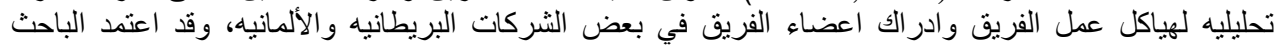

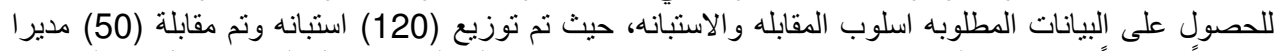

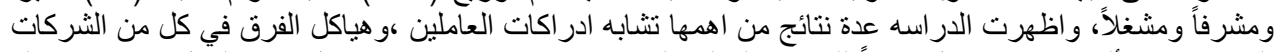

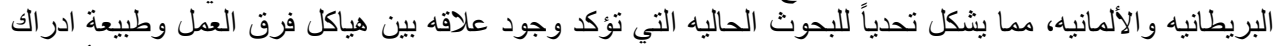

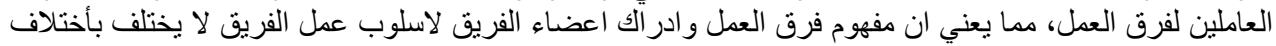

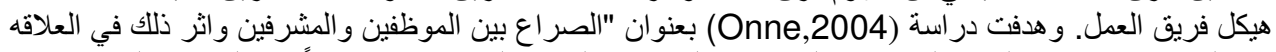

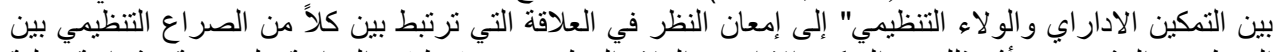

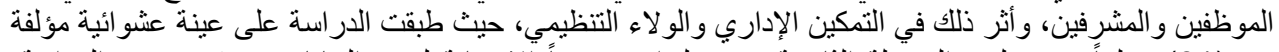

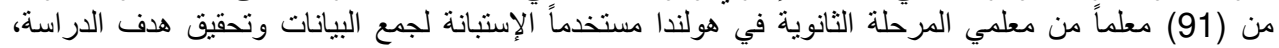

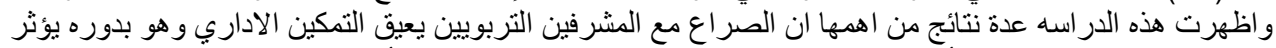

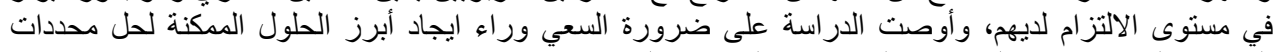

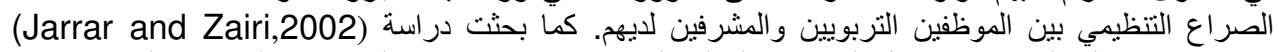

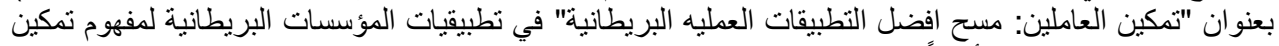

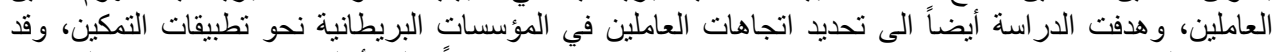

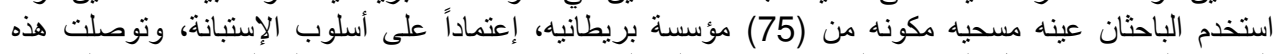

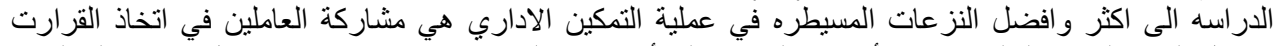

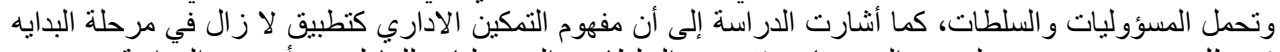

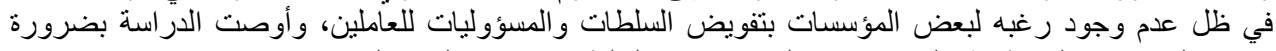

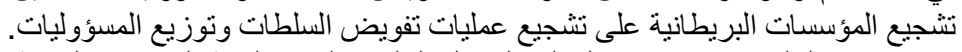
بالتالي، يمكن الإستدلال إلى الجدول النالي كملخص لكافئة الدراسات السابقة التي قد تطرقت إليها الدراسة

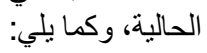

\begin{tabular}{|c|c|c|c|}
\hline النتائج & المنهجية & الههف & الباحثون للاراسة \\
\hline 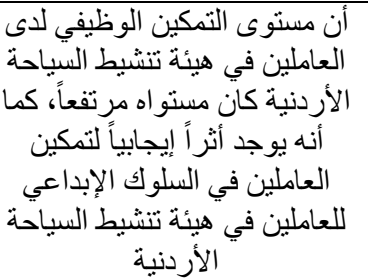 & 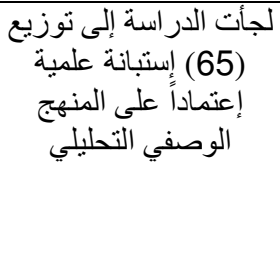 & 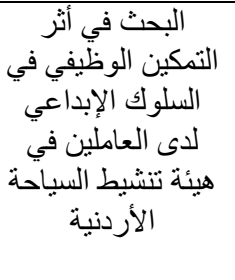 & (محمدية، 2016) \\
\hline
\end{tabular}


Administrative empowerment and its role....

\begin{tabular}{|c|c|c|c|}
\hline 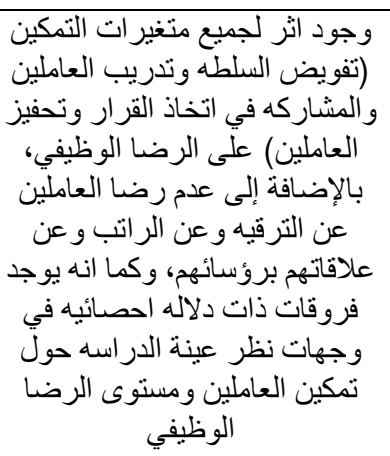 & 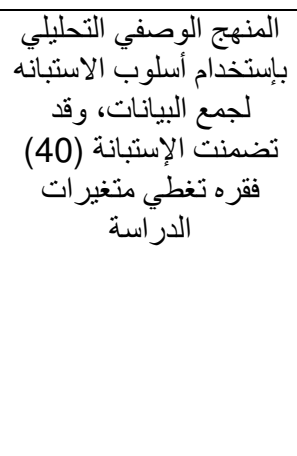 & 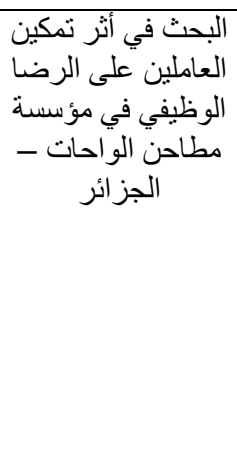 & (بوخلوه وبن قرينة، \\
\hline 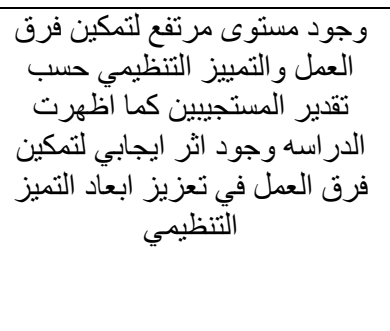 & 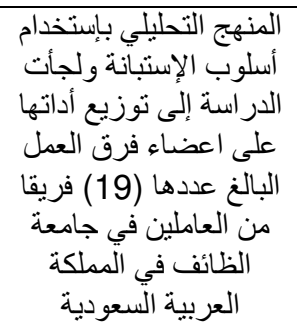 & 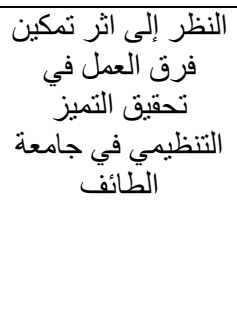 & (النويقة، 2014) \\
\hline 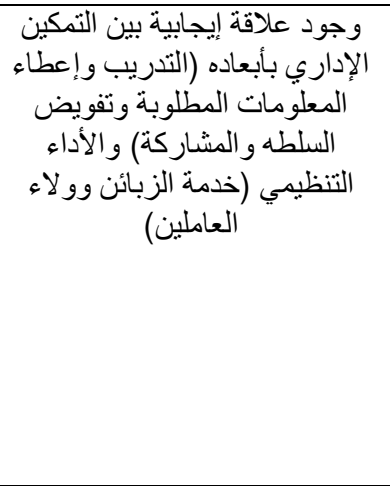 & 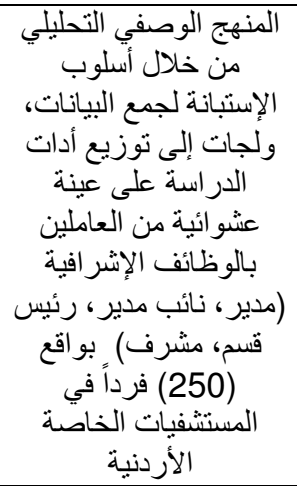 & 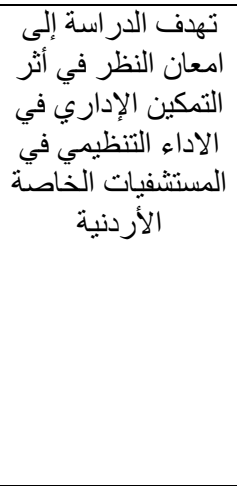 & (أبو عليم، 2014) \\
\hline 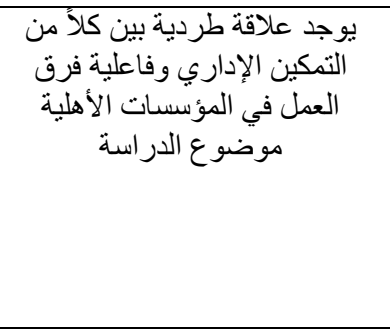 & 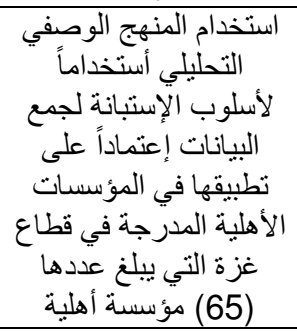 & 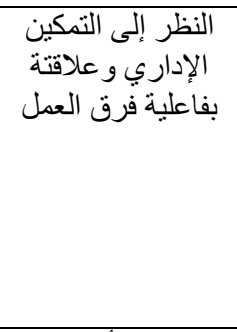 & $\begin{array}{l}\text { (بدير و آخرون، } \\
\text { 2015 }\end{array}$ \\
\hline هنالك علاقة إيجابية بين تمكين فرق العمل & 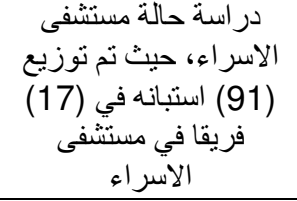 & 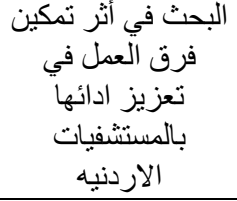 & (السعودي، 2013) \\
\hline 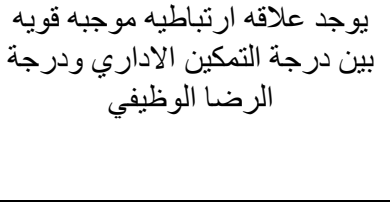 & 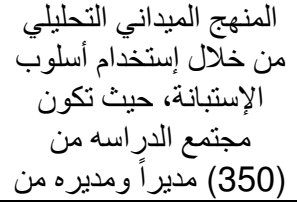 & 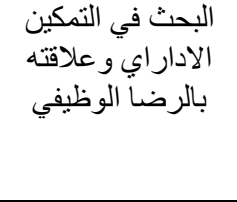 & (الطعاني و السويعي، \\
\hline
\end{tabular}




\begin{tabular}{|c|c|c|c|}
\hline & محافظة الدمام بالمملكه & & \\
\hline وجود علاقة إيجابية بين التمكين & 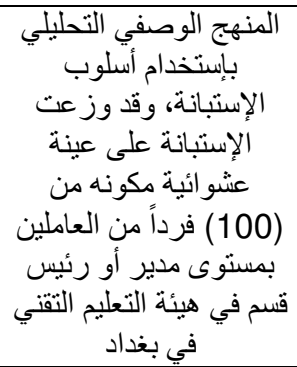 & 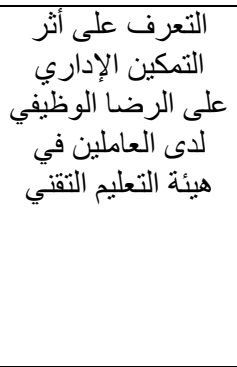 & (عبد الحسين، 2012) \\
\hline 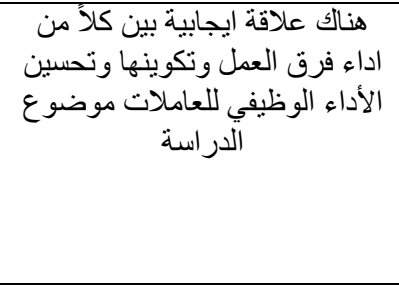 & 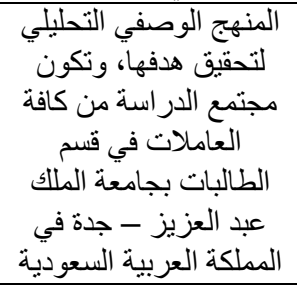 & 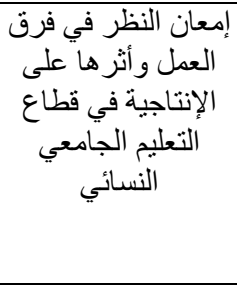 & (عبده، 2011) \\
\hline 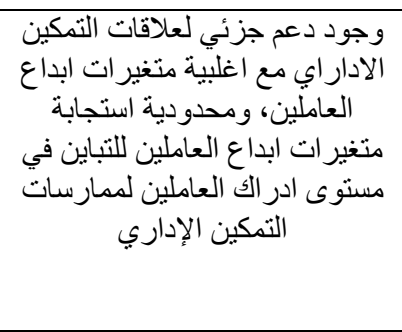 & 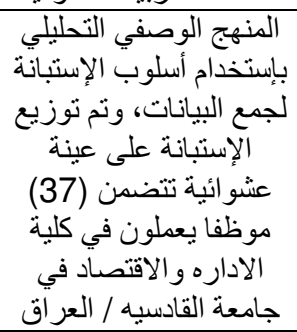 & $\begin{array}{l}\text { التعرف على التمكين } \\
\text { بابداري و علاقته العاملين }\end{array}$ & (ر اضي، 2010) \\
\hline 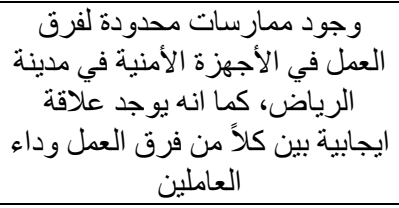 & عن طريق الإستبانة لجميع التيلي & 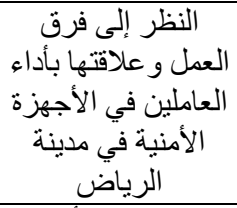 & (الفايدي، 2008) \\
\hline 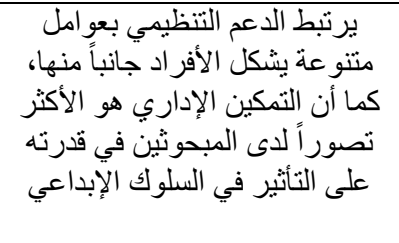 & 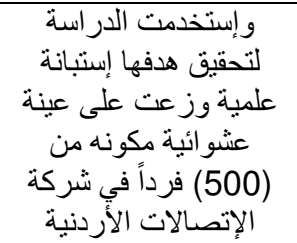 & والتمكين الإداري أثي التئي & $\begin{array}{l}\text { (الدر احشة وصلاح، 2006) } \\
\text { الدينة }\end{array}$ \\
\hline 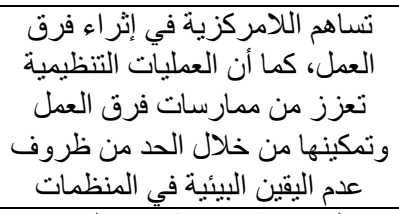 & 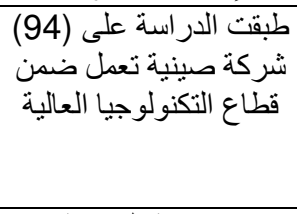 & 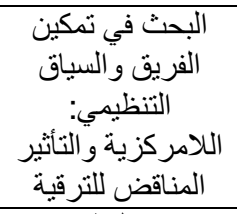 & $\begin{array}{l}\text { Zhang ,2012) } \\
\text { (and Han }\end{array}$ \\
\hline 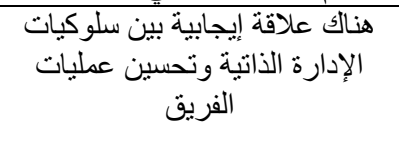 & تكونت عينة الدر اسة من لفريق & إلمعان النظر في الإدارة الفاتية & $\begin{array}{l}\text { 2010) } \\
\text { Rousseau and, } \\
\text { (Aube }\end{array}$ \\
\hline 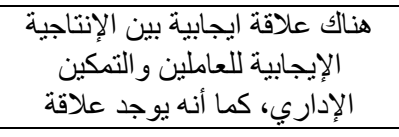 & والإستبانة لجميح البيانات، & التمكين الإداريف بمدر اء & (Carter,2009) \\
\hline
\end{tabular}


Administrative empowerment and its role....

\begin{tabular}{|c|c|c|c|}
\hline ايجابية بين التمكين الإداري و الأداء & من في الو لايات المتحدة مدرجة & & \\
\hline يوجد علاقة بين ممارسات التمكين & 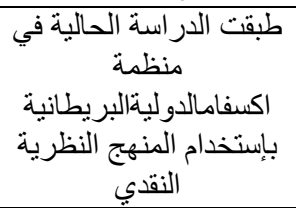 & النظر إلى التمكين المدخل & (Emerson,2008) \\
\hline 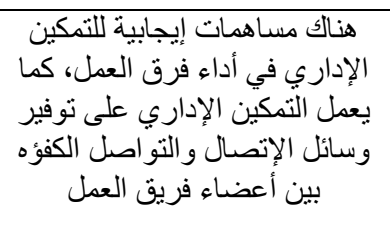 & 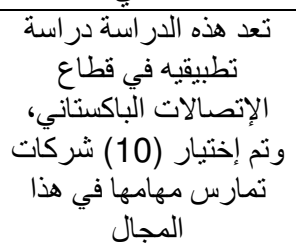 & 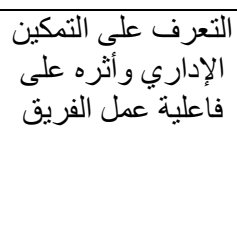 & $\begin{array}{l}\text { Mazhar and ) } \\
\text { ( } 2008 \text {,Khan }\end{array}$ \\
\hline 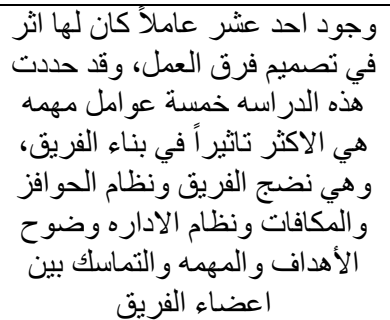 & 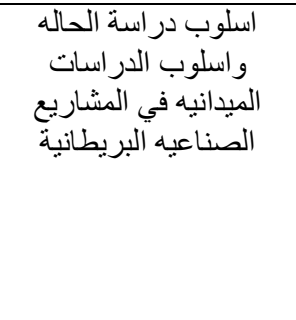 & 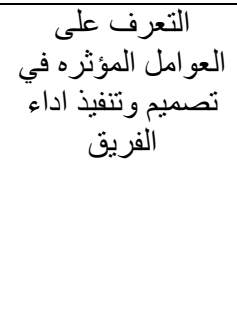 & $\begin{array}{l}\text { (Mendibil and } \\
2006 \\
\text { Macbryde) }\end{array}$ \\
\hline 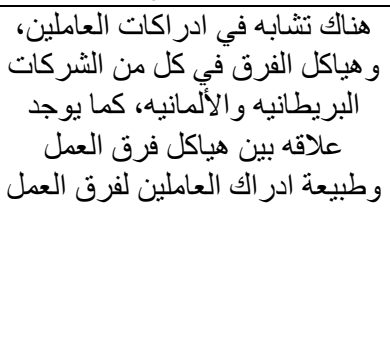 & 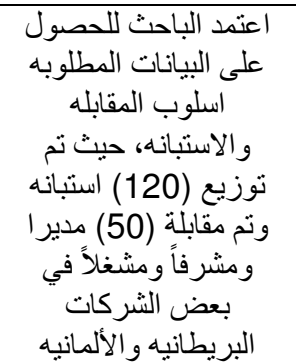 & عمل البحث في هياكل & 2005 ,Frebel \\
\hline 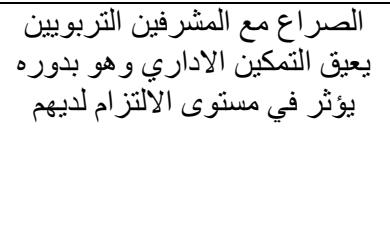 & 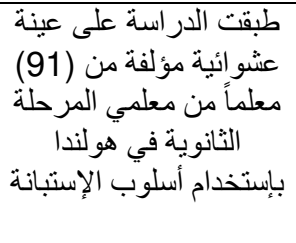 & 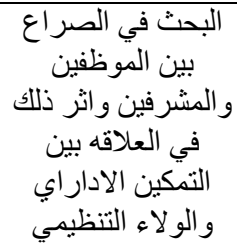 & 2004 ,Onne \\
\hline 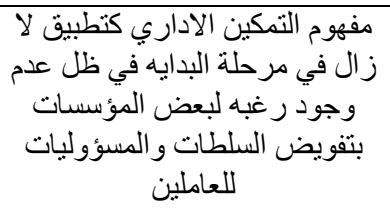 & 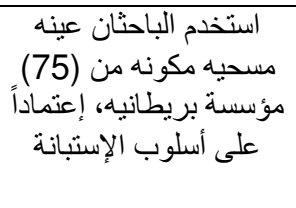 & 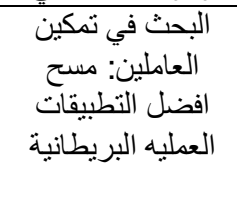 & $\begin{array}{l}\text { (Jarrar and } \\
\text { 2002)،Zairi }\end{array}$ \\
\hline
\end{tabular}

الخاتمة

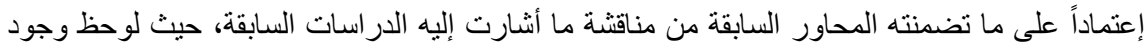

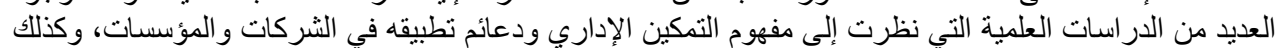

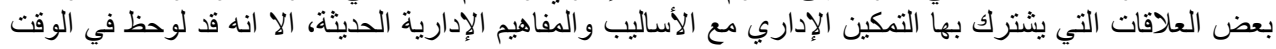




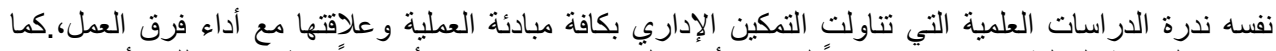

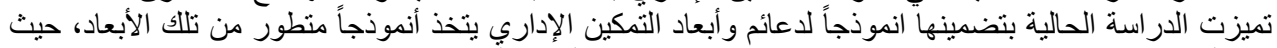

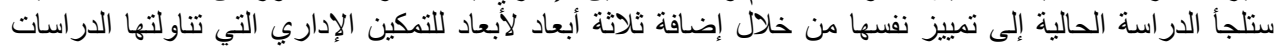

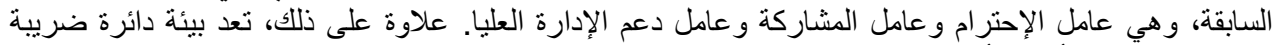

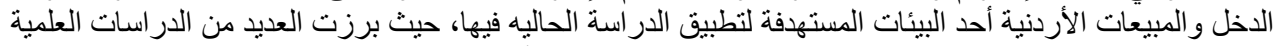

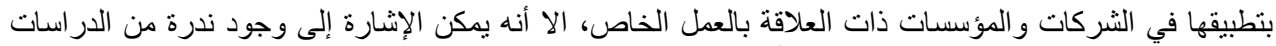

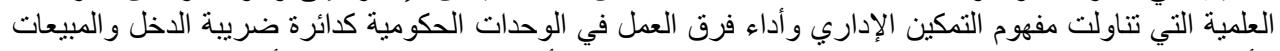

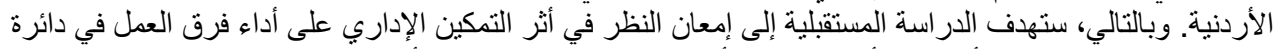

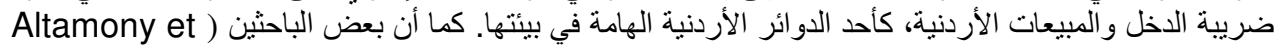
al., 2012; Masa'deh and Shannak, 2012; Masa'deh, 2012, 2013; Shannak et al., 2010; Masa'deh et al., 2008, 2013, 2014, 2015, 2017; Hajir et al., 2015; Kateb et أكدوا على ضرورة قيام الثركات (al., 2015; Obeidat et al., 2016; Vratskikh et al., 2016)

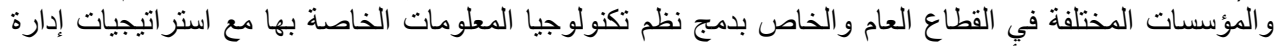

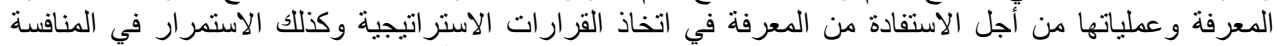

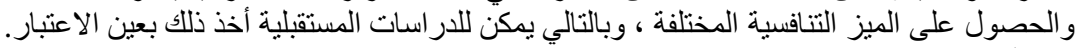

ــ أبو عليم، محمد طالب (2014)، أثر التمكين الإداري في الأداء التنظيمي في المستشفيات الخاصة الأردنية، رسالة

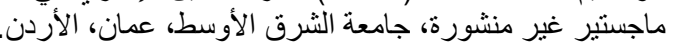

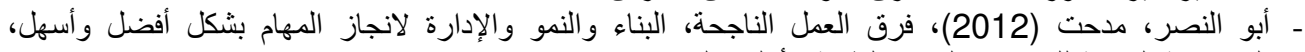

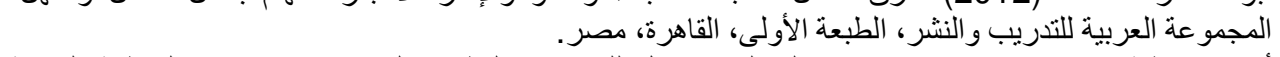

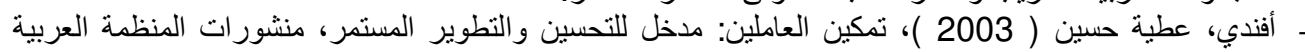

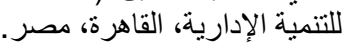

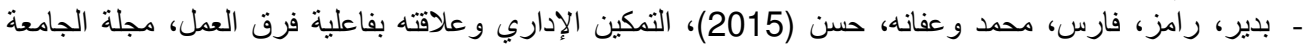

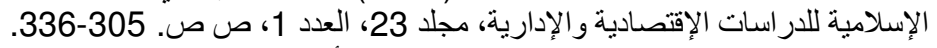

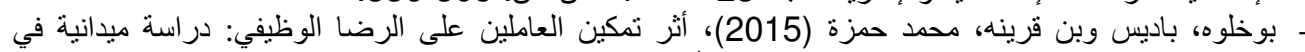

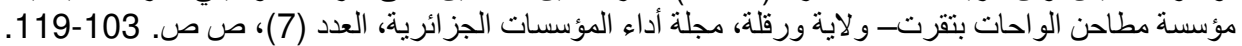

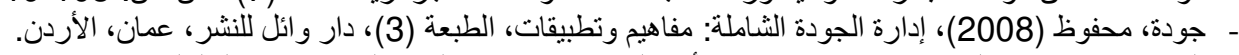

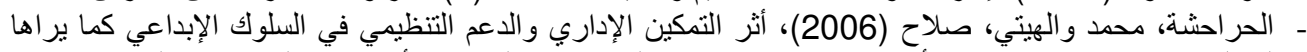

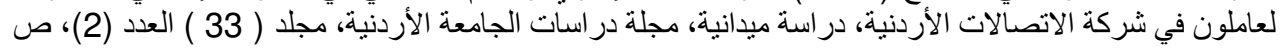

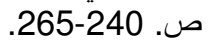

ـ ـ الدوري، زكريا مطلك وصالح، احمد علي ( 2009 ) )، إدارة التمكين واقتصـاديات الثقة في منظمات اعمال الألفية

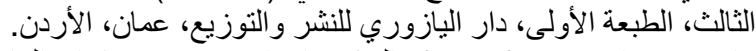

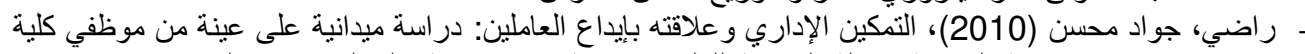

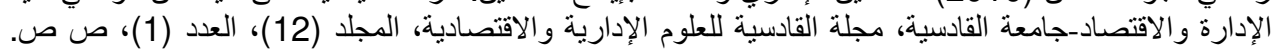
84-62

ـ - الرشيد، عادل وحداد، فريد (2000) ، و اقع فرق الأعمال في منظمات الأعمال الأردنية: دراسة ميدانية لاتجاهات

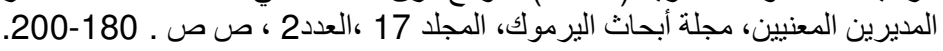

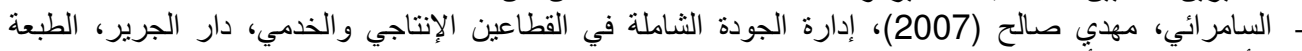
الأولى، عمان-الأردن.

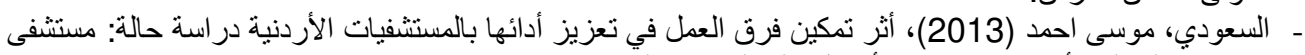

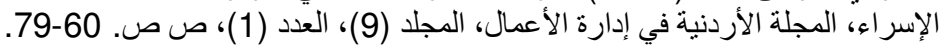

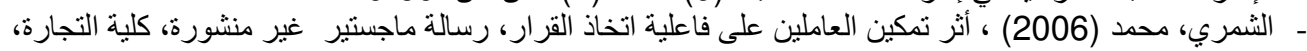

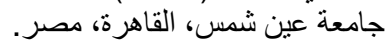
ـ ـ الطائي، رعد عبداله، وعيسى، وقدادة (2008)، إدارة الجودة الثاملة، دار اليازوري العلمية للنشر و التوزيع، عمان -

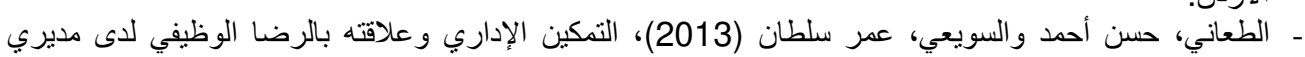

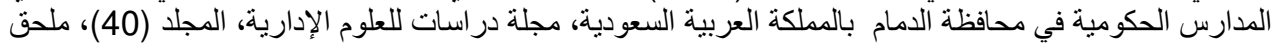

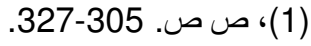




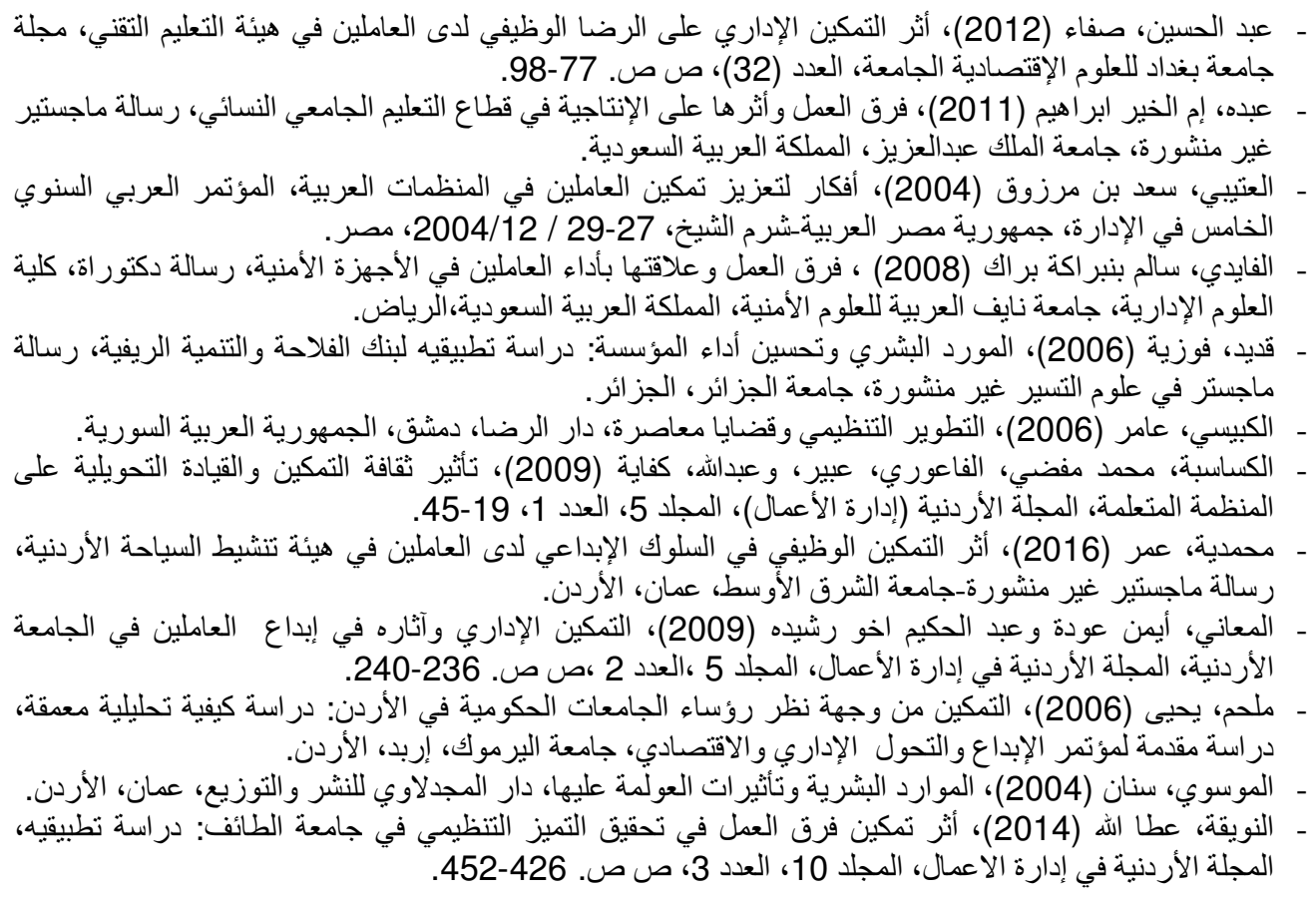

\section{References}

Aburuman, N. (2016). The Impact of Administrative Empowerment on Creativity Improvement among the Workers of Jordanian Public Administration Institute. International Journal of Business and Social Science, 7(1), 182-190.

Al-Ha'ar, H. (2016). The Impact of Administrative Empowerment on the Organization Performance at Jordanian Industrial Companies. Canadian Social Science, 12(1), 19-29.

Al-Magableh, M. W., \& Otoum, A. M. (2014). The Administrative Empowerment and its Relationship with the Innovative Behavior among the Head/Coordinators of the Academic Department at the Faculty of Science and Arts, Sharurah-Najran University. International Research in Education, 2(2), 83-106.

Altamony, H., Alshurideh, M., \& Obeidat, B. (2012). Information Systems for Competitive Advantage: Implementation of an Organizational Strategic Management Process. Proceedings of the 18th IBIMA Conference on Innovation and Sustainable Economic Competitive Advantage: From Regional Development to World Economic, Istanbul, Turkey, 9th-10th May.

Bennis, W.G., \& Townsend, R. (1995). Reinventin Leadership. Collins Business Essential, New York.

Brown, D.R., \& Harvey, D. (200)1An Experiential Approach to Organization Development, (7th ed.), Pearson Prentice Hall, NewJersey, USA. 
Carter, J.D.T (2009). Managers Empowering Employees. American Journal of Economics and Business Administration, 1(2) 39-44.

Emerson, A. (2008). Why Employee Empowerment should be more than just a Buzz Word at Your CU. Credit Union Journal, 81.

Ford, R. C., \& Fottler, M. D. (1995). Empowerment: A Matter of Degree. Academy of Management Executive, 9(3), 21-29.

Frebel, P. (2005). Team Working Structure and Workers Perceptions across National Study in Pharmaceuticals. International Journal of Human Resource Management, 6(2), 256-276.

Hajir, J., Obeidat, B., \& Al-dalahmeh, M. (2015). The Role of Knowledge Management Infrastructure in Enhancing Innovation at Mobile Telecommunication Companies in Jordan. European Journal of Social Sciences, 50(3), 313-330.

Hamed, S. S. (2010). Antecedents and Consequences of Employees Empowerment. Management Review: An International Journal, 5(1), 64-94.

Honold, L. (1997). A Review of the Literature on Employee Empowerment. Empowerment in Organizations, 5 (4), 202-212.

Jarrar, F., \& Zairi, M. (2002). Employee Empowerment. Managerial Auditing Journal, 17(5), 266-271.

Kateb, M., Swies, R., Obeidat, B., \& Maqableh, M. (2015). An Investigation on the Critical Factors of Information System Implementation in Jordanian Information Technology Companies. European Journal of Business and Management, 7(36), 11-28.

Katzenbach, J., \& Smith, D. (1997). The Wisdom of Team: Creating the High Performance Organization, New York: Mckinsey Inc.

Kruja, D., \& Oelfke, T. (2009). The Levels of Empowerment Impact on the Level of Job Satisfaction: The Case of Albanian Hotels. TMC Journal, 4(2), 92.

Masa'deh, R. (2012). The Impact of Management Information Systems (MIS) on Quality Assurance (QA): A Case Study in Jordan. International Journal of Information, Business, and Management, 93-110.

Masa'deh, R. (2013). The Impact of Information Technology Infrastructure Flexibility on Firm Performance: An Empirical Study of Jordanian Public Shareholding Firms. Jordan Journal of Business Administration, 204-224.

Masa'deh, R., \& Shannak, R. (2012). Intermediary Effects of Knowledge Management Strategy and Learning Orientation on Strategic Alignment and Firm Performance.

Research Journal of International Studies, 112-128.

Masa'deh, R., Gharaibeh, A., Maqableh, M., \& Karajeh, H. (2013). An Empirical Study of 
Antecedents and Outcomes of Knowledge Sharing Capability in Jordanian Telecommunication Firms: A Structural Equation Modeling Approach. Life Science Journal, 10(4), 2284-2296.

Masa'deh, R., Gharaibeh, A., Tarhini, A., \& Obeidat, O. (2015). Knowledge Sharing Capability: A Literature Review. In Fourth Scientific \& Research Conference on New Trends in Business, Management and Social Sciences, Istanbul, Turkey, 19-20 September 2015, 1-16.

Masa'deh, R., Hunaiti, Z., \& Bani Yaseen, A. (2008). An Integrative Model Linking ITBusiness Strategic Alignment and Firm Performance: The Mediating Role of Pursuing Innovation and Knowledge Management Strategies. Communications of the International Business Information Management Association (IBIMA) Journal, 2(24), 180-187.

Masa'deh, R., Maqableh, M., \& Karajeh, H. (2014). A Theoretical Perspective on the Relationship between Leadership Development, Knowledge Management Capability, and Firm Performance. Asian Social Science, 10(6), 128.

Masa'deh, R., Shannak, R., Maqableh, M., \& Tarhini, A. (2017). The Impact of Knowledge Management on Job Performance in Higher Education: The Case of the University of Jordan. Journal of Enterprise Information Management, 30(2), 244-262.

Mazhar, A., \& Khan, A. (2008). Impact of Team Empowerment on Team Performance: Case of the Telecommunications Industry in Islamabad. International Review of Business Research, 4(5), 138-146.

Mendibil, K., \& Macbryde, J. (2006). Factor That Affect the Design and Implementation of Team-Based Performance Measurement Systems. International Journal of Productivity and Performance Management, 55(2), 118-142.

Obeidat, B., Al-Suradi, M., Masa'deh, R., \& Tarhini, R. (2016). The Impact of Knowledge Management on Innovation. Management Research Review, 39(10), 1214-1238.

Onne, J. (2004). The Barrier Effect of Conflict with Superiors in the Relationship between Employee Empowerment and Organizational Commitment. Work \& Stress, 18(1), 56-65.

Rousseau, V., \& Aube, C. (2010). Team Self-Managing Behaviors and Team Effectiveness: The Moderating Effect of Task Routineness. Group \& Organization Management, 35(6).

Shannak, R., Obeidat, B., \& Almajali, D. (2010). Information Technology Investments: A Literature Review. Proceedings of the 14th IBIMA Conference on Global Business Transformation through Innovation and Knowledge Management: An Academic Perspective, Istanbul-Turkey, 23rd-24th June, 1356-1368.

Stirr, T. (2003). Fundamentals of Empowerment: Available on:www.4ouncestoheaven.com/fundamentals_of_Empowermentfinal.pdf.

Noe, R., Hollenbeck, J., Gerhart, B., \& Wright, P. (2005). Human Resource Managementm 6th Edition, Pearson Education Ltd. UK. 
Vratskikh, I., Al-Lozi, M., \& Maqableh, M. (2016). The Impact of Emotional Intelligence on Job Performance via the Mediating Role of Job Satisfaction. International Journal of Business and Management, 11(2), 69-91.

Zhang, Z., \& Han, Y. (2012). Team Empowerment and the Organizational Context: Decentralization and the Contrasting Effects of Formalization. Journal of Management, 38(2), 475-501. 